\title{
EL CONCEPTO DE CULPA AQUILIANA Y SU EVOLUCIÓN EN LAS ÚlTIMAS DÉCADAS. DISTINTAS TEORÍAS*
}

\section{Cristián Aedo BARrenA**}

RESUMEN: El presente artículo se divide en dos partes. La primera explica el rol actual de la culpa en los modernos sistemas de responsabilidad civil, en los que la culpa opera como criterio de atribución del régimen común y supletorio de responsabilidad. La segunda parte del artículo analiza las distintas teorías que sobre ella se han formulado en la dogmática: la tesis psicológica, la ética y la normativa, admitida mayoritariamente en la doctrina. Finalmente, un tercer apartado, propone nuestro punto de vista para lo que consideramos una justa apreciación de la culpa. En primer lugar, se argumenta que esta no constituye un reproche moral, sin perjuicio del fundamento moral que subyace en el sistema de responsabilidad; en segundo lugar, la vinculación del componente psicológico en la culpa, todo lo que permite fundamentar un concepto que, admitiendo la tesis de la culpa normativa, incorpore los componentes éticos y psicológicos del instituto.

PALABRAS CLAVE: Responsabilidad civil - culpa - negligencia - concepto normativo.

\section{THE CONCEPT OF AQUILIAN GUILT AND ITS EVOLUTION IN THE PAST FEW DECADES. DIFFERENT THESIS}

ABSTRACT: The present article is divided in two parts. The first part explains the current role of guilt in modern systems of tort law, in which guilt operates as a criterion for allocation of common and residual liability regime. The second part of the article analyzes the different dogmatic

\footnotetext{
Este artículo forma parte del proyecto Fondecyt de iniciación $\mathrm{N}^{\circ} 11121533$, titulado "Las relaciones entre la culpa y la causalidad: una reflexión de la experiencia romana”, del cual el autor es investigador principal y del proyecto Anillo de Investigación Asociativa, patrocinado por la Comisión de Investigación Científica y Tecnológica, bajo el Código SOC 1111: "Estudios dogmáticos del Derecho patrimonial privado", del cual el autor es investigador asociado.

Fecha de recepción: 1 de abril de 2014.

Fecha de aceptación: 22 de julio de 2014.

** Doctor en Derecho por la Universidad de Deusto (España). Profesor de Derecho romano y civil en la Universidad Católica del Norte (CHILE). Correo electrónico: caedo@ucn.cl.
} 
theories developed regarding this subject: the psychological, the ethic and the normative theses, broadly admitted amongst scholars. Finally, a third part, proposes our viewpoint towards what we consider a fair assessment of fault. Firstly, it is argued that it is not a moral reproach, notwithstanding the underlying moral foundation of the liability system. Secondly, the link of the psychological component to guilt, all of which allows substantiating a concept that, while admitting the normative guilt thesis, incorporates the ethical and psychological components of this institute.

KEY WORDS: Tort law - negligence - guilt - normative concept

Sumario: 1. El rol de la culpa en los sistemas modernos de responsabilidad civil. 2. Las tesis sobre el concepto de la culpa. 2.1. Lo que envuelven las tesis sobre el concepto de la culpa. 2.2. La tesis psicológica: la culpa como vulneración de la diligencia. 2.3. El concepto ético de la culpa: el juicio de culpa como reproche personal. 2.4. La posición dogmática mayoritaria: la culpa como concepto normativo. 2.4.1. Tesis normativas versus psicológicas. 2.4.2. ¿Cuándo estamos frente a una tesis normativa? 2.4.3. La culpa como infracción de los reglamentos: culpa contra la legalidad. 2.4.4. La culpa como infracción de los estándares sociales: la posición normativa sustancial. 3. Nuestra opinión. 3.1. Necesaria aproximación desde el fundamento: la culpa no es un reproche moral. 3.2. La relación de la culpa con el componente psicológico: el plano dogmático.

\section{1) EL ROL DE LA CULPA EN LOS SISTEMAS MODERNOS DE RESPONSABILIDAD CIVIL}

Los sistemas de responsabilidad civil, tanto en Chile, como en el derecho comparado, han evolucionado hacia un criterio práctico; buscan, de esta forma, defender de manera más adecuada a la víctima y procurarle el resarcimiento eficaz y oportuno de todo dańo, lo que ha dado lugar a ámbitos en los que la regulación de la responsabilidad responde a factores de imputación diversos de la culpa ${ }^{1}$. Ello está asociado, como dice Valls

\footnotetext{
Véase, en este sentido, Messina de Estrella Gutiérrez, Graciela (1989), "Función actual de la responsabilidad civil", en Felix Trigo Represas y Rubén Stiglitz (directores): Derecho de Daños. Primera Parte, Buenos Aires: La Rocca, p. 39. Bianca, Cesare Massimo (1997): "Supervivencia de la teoría de la culpa", trad. por Alberto J Bueres, en Aída Kemelmajer de Carlucci y Jesús Alberto Bueres (directores): Responsabilidad por daños en el Tercer Milenio. Homenaje al profesor Doctor Atilio Anibal Alterini, Buenos Aires: Abeledo-Perrot, p. 137, explica que la culpa perdió paulatino protagonismo por su imposibilidad para resolver el fenómeno de la masificación de los daños. Y como indica GHersi, Carlos (1997), "Responsabilidad por actos lícitos", en Aída Kemelmajer de Carlucci y Jesús Alberto Bueres
} 
Portell, a una evolución del sistema concebido como mecanismo de castigo a uno de reparación, del acento centrado absolutamente en la persona del culpable, hasta las nuevas legislaciones en las que el énfasis está puesto en la víctima ${ }^{2}$.

En efecto, tanto el sistema fundado en la culpa, como el denominado de responsabilidad estricta permiten la distribución de riesgos sociales. Un sistema fundado en la culpa delimita un radio de actividades de las que el potencial autor del daño debe hacerse cargo, reservando un ámbito en el que la propia víctima debe asumir su propio cuidado. En cambio, los sistemas de responsabilidad estricta se justifican en la medida que la actividad supone un riesgo intrínseco o las medidas de cuidado que la propia víctima puede adoptar resultan superfluas ${ }^{3}$. Es decir, siguiendo

(directores): Responsabilidad por daños en el Tercer Milenio. Homenaje al profesor Doctor Atilio Aníbal Alterini, Buenos Aires: Abeledo-Perrot, p. 477, había que transformar al dañado en damnificado, con toda la connotación ideológica que importaba en el campo del Derecho, modificando la visión disciplinadora por otra reparadora.

2 Valls Portell, Roberto (1992), "El Derecho de Daños en la práctica actual”, en L. Ribó Durán (a cargo de): Derecho de Daños, Bosch: Barcelona, p. 70. A nuestro juicio, la insuficiencia de la culpa no se mostró como consecuencia de su carácter individualista y de reproche moral, sino simplemente porque las actividades de riesgo importaron nuevas realidades, comprendiendo en ellas actividades de peligro intrínseco. Ello es sin perjuicio de que de la lectura histórica no puede afirmarse que el principio hubiere sido el de que solo hay responsabilidad por culpa. El Derecho romano asignó varias funciones a la culpa, en el contexto de la lex Aquilia, de modo que la acción de la ley se otorgó también en casos en los que la conducta no podía calificarse, en estricto rigor, de culposa. Para este problema, remitimos a nuestros trabajos Aedo Barrena, Cristián (2012), "La función de la culpa en el sistema de la responsabilidad civil: una lectura desde el Derecho romano es posible", en Fabián Elorriaga de Bonis (coordinador): Estudios de Derecho Civil VII, Santiago: AbeledoPerrotThomson Reuters, pp. 777-784 y Aedo Barrena, Cristián (2009), "La acto legis Aquiliae: concepto, características y desarrollo decretal posterior. Lecturas desde el capítulo tercero", en Revista de Derecho de la Universidad Católica del Norte, 16, 1, pp. 23 y ss. De paso, digamos que el pretendido carácter penal del delito de damnum, suponiendo que tenía características idénticas a nuestra idea moderna de pena, no se encontraba emparentado con la idea de la culpa. Por el contrario, la culpa se utilizó a menudo como herramienta de extensión de los presupuestos de aplicación de la ley.

3 Un mecanismo intermedio entre el régimen de culpa y un sistema de responsabilidad estricta, es el que se ha sostenido como presunción general de culpa por hecho propio. En efecto, una parte importante de la doctrina reciente, no obstante concluir que la presunción del artículo 2329 supone actividades intrínsecamente peligrosas, admiten junto con ello una presunción general de responsabilidad por hecho propio, en atención al principio re ipsa loquitur. Por todos, Barros, quien señala: "la regla de presunción de culpa por el hecho propio tiene su antecedente más general en una máxima fundada en la experiencia: el solo hecho del accidente puede ser indicio prima facie de la culpa de quien desarrolla la actividad. La máxima latina res ipsa loquitur, dejad que las cosas hablen por si mismas, que se emplea en el common law, es expresiva de la condición de aplicación más general de la presunción: la experiencia enseña que en ciertos casos el daño puede ser más bien atribuido a negligencia que a un hecho que escapa al cuidado del agente”. Barros Bourie, Enrique (2009), Tratado de Responsabilidad Extracontractual, Santiago: Editorial Jurídica de Chile, reimpresión de la $1^{\text {a }}$ edición, p. 153. Véase también Schiele, Carolina y Tocornal, Josefina (2010), "Artículo 2329 del Código Civil. La interpretación de presunción por hechos propios existe en la jurisprudencia”, en Revista Chilena de Derecho, vol. 37, No 1, p. 139 
en este punto a Barros, las diferencias entre un sistema por culpa y otro de responsabilidad estricta radica en el enfoque: mientras el régimen de culpa -aunque presunta- se focaliza en la conducta del agente, la responsabilidad estricta atiende al defecto de unidad que resulta de la actividad ${ }^{4}$.

Esta perspectiva ha sido sostenida, por ejemplo, por Medina Alcoz, para quien el sistema de responsabilidad contiene dos principios que pueden diferenciarse claramente: el de la culpa y el del riesgo derivado de actividades peligrosas. Para la autora, la responsabilidad por riesgo supone una actividad peligrosa en sí misma, en la que se entiende integrada la idea de culpa5. Como dice Barros: "La responsabilidad por culpa tiene un elemento objetivo que la aleja del reproche personal; pero esa objetividad es radicalizada en el caso de la responsabilidad estricta, porque esta no requiere siquiera que la conducta sea objetivamente reprochable"6.

El panorama normativo que puede vislumbrarse en el sistema chileno de responsabilidad, así como en la mayoría de los países continentales, es sin perjuicio de fenómenos sociales que, al margen de críticas históricas a la culpa ya superadas, han puesto en cuestión el papel de la culpa. ${ }^{7} \mathrm{De}$

\section{Barros (2009) 448 y ss.}

Medina Alcoz, María (2004), "El debate histórico de la subjetividad versus la objetividad de la responsabilidad civil en Francia y su proyección en España. El equilibrio de su convivencia actual en el Derecho espańol”, en González Porras, J.M. Méndez González, F.P. (coordinadores), Libro Homenaje al profesor Manuel Albaladejo García, Murcia: Colegio de Registradores de la Propiedad y Mercantes de España, Universidad de Murcia, t. I, pp. 3219 y ss. Sobre el tema véase Medina Alcoz, María (2003), La culpa de la víctima en la producción del daño extracontractual, Madrid: Dykinson, pp. 57 y ss. Un planteamiento similar ha sostenido Reglero Campos, L. Fernando (2008), Tratado de Responsabilidad Civil, cap. II: Los sistemas de responsabilidad civil, Madrid: Thomson-Aranzadi, 4a edición, t. I, pp. 22832285, quien estima que el ordenamiento espańol contiene un problema al no contemplar una norma general de imputación por riesgos, de modo que la culpa, al tener unos límites poco definidos, sigue constituyendo un criterio perfectamente válido para las situaciones de riesgo. Para un sistema como el del common law, véase Owen, David (1997), "Philosophical Foundations of fault in Tort Law", en el mismo (editor), Philosophical foundations of Tort Law, Oxford: Clarendon Paperbacks, pp. 201-202.

6 Barros (2009) 445.

7 Para la crítica histórica de la culpa, véase, por todos, sobre estos defectos de la culpa, RoDotÀ, Stefano (1965), Il problema della responsabilità civile, Milano: Giuffrè, pp. 18-25. Según el autor, el rígido principio de responsabilidad por culpa partía del supuesto de una economía de escala menor, en la que gran parte de los daños podían atribuirse a la fatalidad. En cambio, en una economía de mayor desarrollo, no solo aumentaba el número de daños, sino que había nuevas hipótesis de lesiones. En relación con el desconocimiento del autor del daño, Rodotà piensa que: “... una società ben organizzata non può tollerare che un danno non sia risarcito sol perchè è difficile o impossibile risalire al suo autore, si dice cosa ovvia”. Véase también, para las dificultades que supuso la culpa codificada en una sociedad industrializada, Ripert, Georges (1949), La règle morale dans les obligations civiles, París: LGDJ, 4a edición, pp. 200-203. Desde el punto de vista filosófico, el desarrollo de la idea del riesgo, siguiendo a Mazeaud, Henri, Mazeaud, Leon y Mazeaud, Jean (1978), Lecciones de Derecho Civil part. II, vol. II: La responsabilidad civil. Los cuasicontratos, trad. por Luis Alcalá Zamora y Castillo, Buenos Aires: Montchrestein, pp. 6-7 se debió a la importante influencia de la escuela histórica, cuya idea arranca de la evolución fatal del Derecho, desde concepciones 
un lado, en cuanto la culpa designaba el patrimonio sobre el cual se hacía efectiva la responsabilidad del deudor, los sistemas de seguros y colectivos se tradujeron, en los hechos, en un reemplazo o declive de la culpa ${ }^{8}$, pero, como contrapartida, comenzó a emplearse en la valoración de los perjuicios, estimando la gravedad de la falta como un mecanismo de recuperación de sus primigenias funciones preventivas y punitivas ${ }^{9}$. No solo eso, sino que como advierte De Ángel, hay amplios campos en los que el concepto de la culpa se ha ido deformando, no solo por la objetivación legislativa, sino porque en determinados terrenos problemáticos la jurisprudencia ha estrechado el concepto de la culpa al punto de convertirla en una responsabilidad estricta, como ocurre con la responsabilidad del empresario $^{10}$.

Sin perjuicio de lo anterior, como se ha dicho supra, la culpa ha ido retomando un papel protagónico, especialmente en el caso de la responsabilidad civil de los profesionales en el sistema español. Como nuevamente advierte De Ángel, la jurisprudencia viene descartando toda clase de responsabilidad más o menos objetiva, sin que admita la inversión de la carga de la prueba admitida como doctrina del TS, tratándose de profesionales (especialmente sanitarios) ${ }^{11}$. En el Derecho chileno, puede hacer-

subjetivas hasta objetivas, cuyo sentido era la mejor protección de las víctimas, la progresiva separación entre responsabilidad penal y civil, que importaba no asimilar el resarcimiento con la sanción y, en este sentido, con la culpa, que fue juzgada como prescindible.

8 Viney, Geneviève (1965), Le déclin de la responsabilité individuelle, Paris: LGDJ, pp. 211; 215 y ss. Aunque debemos advertir que Viney se refiere a una amplia gama de figuras, incluyendo en ellas las responsabilidades objetivadas por dańos de las cosas y del guardián, la responsabilidad de pleno derecho en determinadas hipótesis, como en el supuesto del profesional en relación con sus clientes, materias en las que, desde luego, no podemos detenernos.

9 Viney (1965) 305 y ss.

10 De Ángel Yágüez, Ricardo (1995), Algunas previsiones sobre el futuro de la responsabilidad civil (con especial atención a la reparación del daño), Madrid: Civitas, pp. 32-33. De ÁNGEL YÁGüEz, Ricardo (1993), Tratado de responsabilidad civil, Madrid: Civitas, $3^{a}$ edición, pp. 351 y ss. Jourdain, Patrice (1994), Les principes de la responsabilité civile, Paris: Dalloz, 2a edición, p. 16 también ha denunciado una progresiva deformación del concepto de culpa a través de las decisiones de los tribunales, quienes han llegado a considerar como culpa simples errores moralmente insignificantes, fruto de la torpeza o el mal manejo, lo que trae el peligro de confundir el error con la culpa, insistiendo, de la mano de Tunc, sobre el carácter estadísticamente inevitable y por tanto, perdonable de ciertos descuidos. En Chile, en algunos ámbitos, como la responsabilidad por accidentes de trabajo, algunos autores ya han manifestado este problema, al sostener que la jurisprudencia ha conducido a hacer responsable al empleador por la culpa levísima. Véase Diez Schwerter, José Luis (2005), "La culpa del empresario por accidentes del trabajo: modernas tendencias jurisprudenciales”, en Baraona González, Jorge y Zelaya Etchegaray, Pedro (editores), La responsabilidad por accidentes del trabajo, en Cuadernos de Extensión Jurídica, $\mathrm{N}^{\circ} 10$, p. 85

11 De Ấngel (1995) 35-40. Véase también De Ángel YágüEz, Ricardo (1994), "La responsabilidad civil de los profesionales y de las Administraciones sanitarias", en AA.VV.: La responsabilidad de los profesionales y de las Administraciones sanitarias, Sevilla: Consejería de Salud Junta de Andalucía, pp. 37 y ss. Como afirma Asua González, Clara I. (2008), en L. Fernando Reglero Campos (coordinador): Tratado de Responsabilidad Civil, cap. XIII: Responsabilidad Civil Médica, Madrid: Thomson-Aranzadi, 4a edición, t. II, p. 733, tres ex- 
se una afirmación similar, incluso tratándose de la responsabilidad de los servicios de salud ${ }^{12}$.

De este modo, se afirma, la culpa constituye el factor atributivo nodal sobre el cual se articula el régimen común ${ }^{13}$. En el Derecho chileno se advierte idéntico consenso ${ }^{14}$. Esta perspectiva que viene describiéndose

tremos destacan en el sistema de responsabilidad configurado por la jurisprudencia: el igual tratamiento a efectos de imputación de daños en los sistemas de responsabilidad contractual y extracontractual; la consideración de los deberes de los profesionales médicos como obligaciones de medios; y, la obligación de probar la culpa. Específicamente en el caso de los médicos, interesante es el trabajo de LLamas Ромво, Eugenio (2000), "Responsabilidad médica, culpa y carga de la prueba”, en Juan Antonio Moreno Martínez (coordinador): Perfiles de la responsabilidad en el Nuevo Milenio, Madrid: Dykinson, pp. 297 y ss., trabajo en el que, en términos generales, se refiere a los mismos extremos antes expresados.

12 Véase, por todos, Cárdenas Villarreal, Hugo y Moreno Molinet, Jaime (2011), Responsabilidad médica. Estándares jurisprudenciales de la falta de servicio, Santiago: Abeledo PerrotThomson Reuters, pp. 47 y ss.

13 En este sentido, Dítz-Picazo, Luis y Gullón, Antonio (2005), Sistema de Derecho Civil, vol. II: El contrato en general. La relación obligatoria. Contratos en especial. Cuasicontratos. Enriquecimiento sin causa. Responsabilidad extracontractual, Madrid: Tecnos, $5^{\text {a }}$ reimpresión 9a edición, p. 540. Díez-Picazo (2001) 164. De Ángel (1993) 126-127. Como magnífica síntesis, Ribot Igualada, Jordi (2003), "La culpa "relevante" como culpa "adicional": La STC 181/2000 a la luz de la interacción entre responsabilidad objetiva y culpa”, en Antonio Cabanillas Sánchez y otros (coordinadores): Estudios juridicos en Homenaje al profesor Luis Diez-Picazo, t. II: Derecho Civil. Derecho de Obligaciones, Madrid: Thomson-Civitas, p. 2884 explica que: "La responsabilidad por culpa es el fundamento de responsabilidad que se aplica cuando no existe, para el supuesto de hecho contemplado, otra norma aplicable. La responsabilidad por culpa es, en este sentido, subsidiaria porque opera como norma general a falta de regla especial. Pero además, en tanto que norma general, también puede ser calificada por su efecto como regla supletoria, complementadora o de integración, en el sentido que puede ser empleada como fundamento alternativo de la obligación indemnizatoria y ser aplicada pese a la existencia de una norma especial de responsabilidad civil objetiva para este tipo de supuestos". Expresamente contrario a esta perspectiva, Rogel VIDE, Carlos (1977), La responsabilidad civil extracontractual. Introducción al estudio jurisprudencial, Madrid: Civitas, p. 25, quien además de hacerse cargo de las críticas de Rodotà -el triple prejuicio que presidiría la idea de la culpa-, afirma que el sistema de la culpa, a pesar de la tradición y del artículo 1902, tiene un carácter residual. Un punto de vista interesante formula Medina Alcoz, María (2004), "El debate histórico de la subjetividad versus la objetividad de la responsabilidad civil en Francia y su proyección en España. El equilibrio de su convivencia actual en el Derecho español”, en J.M. González Porras y F.P. Méndez González (coordinadores): Libro Homenaje al profesor Manuel Albaladejo García, Murcia: Colegio de Registradores de la Propiedad y Mercantiles de España, Universidad de Murcia, t. I, pp. 3223 y ss., para quien el sistema de responsabilidad contiene dos principios que pueden diferenciarse claramente: el de la culpa y el del riesgo derivado de actividades peligrosas y ambos pueden formularse con carácter general, evitando un concepto monstruoso de la culpa, que abarque indefinidamente situaciones en las que propiamente hablando no concurre el requisito. En este sentido, establecida que la responsabilidad por riesgo supone una actividad peligrosa en sí misma y suponiendo un principio general de la responsabilidad, como la culpa, es que ha propuesto el establecimiento de una regla general, que opere junto con la culpa, a partir de la interpretación analógica de los preceptos del Código civil que disponen una responsabilidad estricta. Sobre el tema véase Medina Alcoz, María (2003), La culpa de la víctima en la producción del daño extracontractual, Madrid: Dykinson, pp. 57 y ss.

14 En la dogmática chilena, véanse, entre otros, BArros (2009) 16; 27-28; 75; Corral (2004) 73; Rodríguez Grez (1999) 63. 
ha sido enfrentada, explícita o implícitamente, desde las funciones de la responsabilidad, de modo que se puede afirmar que la culpa se mantiene como régimen común porque dicho elemento permite cumplir, conforme se ha señalado, la función estrictamente reparatoria o predominantemente resarcitoria ${ }^{15}$. Como indican Salvador y Castiñeira, la función compensatoria está emparentada específicamente con uno de los fundamentos básicos de la imputación del daño, como es la culpa ${ }^{16}$.

\section{2) LA TESIS SOBRE EL CONCEPTO DE LA CULPA}

\section{1) LO QUE ENVUELVEN LAS TESIS SOBRE LA CULPA}

¿Qué esconde esta discusión sobre las funciones, en otras palabras, por qué repercuten como lo hacen sobre el concepto de la culpa? La respuesta debe buscarse en el ámbito que podemos denominar intra-

15 En este sentido, Llamas Pombo, Eugenio (1999), Cumplimiento por equivalente y resarcimiento del daño al acreedor, Madrid: Trivium, pp. 85 y ss. Pantaleón Prieto, Fernando (2001), "Cómo repensar la responsabilidad civil (también de las Administraciones públicas)", en el mismo (a cargo de): La responsabilidad en el Derecho, Madrid: AFDUAM, pp. 175-177; también publicado en Juan Antonio Moreno Martínez (2000), Perfiles de la responsabilidad civil en el Nuevo Milenio, Madrid: Dykinson, pp. 6-12, para quien las normas de la responsabilidad civil de hecho pueden provocar prevención, al disuadir tener que pagar cierta suma de dinero; el legislador, satisfechos los criterios de justicia conmutativa puede optar por un sistema que reduzca la frecuencia de los daños -sin sacrificar las exigencias compensatorias por las preventivas-; y que, a los efectos del juicio de diligencia o negligencia es esencial comparar los costes de las medidas de precaución disponibles (incluida la cesación o disminución de la actividad de que se trate), pero que todo ello no implica que la prevención constituya una función normativa de la responsabilidad civil extracontractual. Ha formulado juicios similares, analizando esta vez los rasgos de la responsabilidad en el sistema español en Pantaleón, Fernando (1991), “Comentario al artículo 1902”, en Cándido Paz-Ares Rodríguez, Luis Díez-Picazo Ponce de León, Rodrigo Bercovitz y Pablo Salvador Coderch (directores): Comentarios al Código Civil, Madrid: Ministerio de Justicia, t. II, pp. 1971-1973. Díez-Picazo (1999) 47, admite que pueda haber una prevención, tanto general, como especial, como un impulso psicológico para el ciudadano que trata de evitar las consecuencias desfavorables de la norma; y, la prevención especial, en cuanto se influye en las acciones futuras de una persona. En el mismo sentido, De Ángel (1993) 60-61. La forma en la que se describe dicha relación, como se aprecia, tiene estricta relación con lo que Díez-Picazo ha denominado como función demarcatoria y con lo que Barros Bourie, Enrique (2005), "Justicia y eficiencia como fines del Derecho”, en Juan Andrés Varas Braun y Susan Turner Saelzer (coordinadores): Estudios de Derecho Civil. Jornadas Nacionales de Derecho Civil. Valdivia. 2005, Santiago: LexisNexis, p. 16 identifica, como fundamento, con la justicia correctiva: "Así, en la responsabilidad civil, hay lugar a una relación obligatoria entre el responsable y la victima, porque aquel ha infringido un deber o ha asumido un riesgo que le debe ser atribuido causando un daño, de modo que la victima tiene el derecho a ser restablecida a la situación anterior en razón de ese hecho".

16 Salvador Coderch, Pablo y Castiñeira Palou, María Teresa (1997), Prevenir y castigar. Libertad de información y expresión, tutela del honor y funciones del Derecho de daños, Barcelona: Marcial Pons, p. 107. 
sistémico, es decir, en el rol que la culpa juega dentro del sistema de responsabilidad, en la relación con los demás elementos. Desde este punto de vista, el papel de la culpa en el terreno de las funciones obedece a las concepciones que se tengan en relación con los vínculos de la culpa con la conducta, la antijuridicidad o la causalidad.

Enunciemos brevemente qué cuestiones problemáticas muestra la culpa en relación con la causalidad. Tómese nota, por ejemplo, de una argumentación como la siguiente: para diferenciar culpa de la causalidad normativa, adecuada, se recurre al expediente de afirmar que la culpa tiene un fundamento moral y subjetivo, con lo que se oculta, de momento, la culpa estricta -como desatención de un estándar objetivo-. Luego, se afirma derechamente que la culpa estricta no implica un reproche moral. En otro tipo de argumentaciones se reconoce el problema y se busca la solución al indagar en objetivas diferencias entre el tipo de previsibilidad presente en la culpa y en la causalidad normativa. Otros, entendiendo que el juicio de causalidad normativa es tributario de la culpa, tienden a pensar que las distancias entre la responsabilidad objetiva y subjetiva son difusas, como en la escuela del análisis económico en España. Y un tercer grupo niega dicha dependencia de la causalidad a la culpa, afirmando el carácter ontológico de la primera, queriendo separar el rol de previsibilidad en los elementos normativos incorporados en la causalidad y los utilizados en la culpa ${ }^{17}$.

En relación con la antijuridicidad, si se define la culpa como la vulneración de una norma, de un deber de conducta, nacen cuestionamientos que legítimamente pueden surgir de esta perspectiva: ¿cómo se concilia dicho concepto con la antijuridicidad? Desde luego, se han presentado alternativas: una posibilidad es negar la antijuridicidad como requisito de un sistema de responsabilidad. Una segunda, afirmar, por un lado, que culpa-antijuridicidad son lo mismo y luego reconocer que para ciertas parcelas del ordenamiento la antijuridicidad es exigida, en el supuesto que el ordenamiento vincule el daño con la violación de derechos subjetivos. También podría abordarse la cuestión del siguiente modo: vincular la antijuridicidad no con la conducta, sino con el daño, como ocurre con buena parte de la dogmática italiana, al adoptar el artículo 2043 del Codice civile la exigencia de un daño injusto; que la culpa incluye un momento de antijuridicidad (dogmática francesa); distinguir perfectamente los institutos, lo que conduce a algunos a proponer un concepto de culpa como

17 Remitimos nuevamente a nuestro artículo Aedo (2012) 784 y ss.; y, Aedo Barrena, Cristián (2010), "El uso de estacionamiento como acto de consumo. Reflexiones sobre la causalidad y la culpa. Comentario a la sentencia de la Corte de Apelaciones de Antofagasta, 30 de marzo de 2010", en Revista de Derecho de la Universidad Católica del Norte, № 1, pp. 213-239. 
reproche social o bien mantener el concepto de vulneración de un deber de cuidado, afirmando por otra parte la antijuridicidad ${ }^{18}$.

¿Qué es, por tanto, la culpa para la responsabilidad civil extracontractual? Siguiendo a Díez-Picazo, pueden encontrarse en la dogmática al menos cuatro concepciones en relación con el concepto de la culpa: psicológica, ética, normativa y económica ${ }^{19}$. Maiorca, por su parte, reconoce tres acepciones para la expresión: como sinónimo de causa, como omisión de la diligencia y como vulneración de una norma de cuidado. El primer sentido corresponde al empleo ordinario de la expresión. El segundo obedece a la tesis psicológica y la última a la teoría normativa ${ }^{20}$. En la dogmática francesa, como indica Viney, buena parte del desorden reinante deriva de las diversas definiciones que se proponen para la faute; a) la noción moral de la culpabilidad; b) otros sostienen un concepto objetivo de la faute, imputable al autor cuando el acto es socialmente peligroso o nocivo, negando cualquier parentesco entre la culpa moral y la jurídica; c) la posición intermedia: la faute se considera como una noción, en principio subjetiva, pero libre de consideraciones psicológicas que, aunque conteniendo o incorporando principios morales, engloba actos moralmente indiferentes ${ }^{21}$. Veamos cuáles son estas distintas teorías sobre la culpa.

\section{2) LA TESIS PSICOLÓGICA: LA CULPA COMO VULNERACIÓN DE LA DILIGENCIA}

Como explica Díez-Picazo, la corriente psicológica tiene su origen en el Derecho penal del primer positivismo y corresponde a un concepto causalista del Derecho, en el que los elementos objetivos quedaban radicados en la antijuridicidad, los subjetivos en la culpabilidad y la causalidad era concebida en términos materiales, pero indica, siguiendo a Mir Puig, que dicha concepción fracasó tratándose de la culpa inconsciente o sin representación, en la que no existe ninguna conexión psíquica entre el autor y la lesión ${ }^{22}$. Esta definición se encuentra presente cada vez que se la define como la simple omisión de la diligencia o la falta de cuidado, sin agregar ningún elemento normativo al concepto.

Se trata de una opinión que uno puede encontrar frecuentemente en autores de la primera mitad del siglo pasado, en cualquier sistema, cuya nota común es centrar, como elemento fundamental de la culpa, la previsibilidad de la conducta. Desde esta perspectiva, por ejemplo, en su clási-

\footnotetext{
18 Nuevamente, remitimos a nuestro trabajo AEDo (2012) 786-791.

19 Díez-Picazo (1999) 350 y ss. Véase también Díez-Picazo (2011) 253.

20 Maiorca, Carlo (1960), "Colpa civile. (teoría generale)", en Enciclopedia del Diritto, Milano: Guiffrè, t. VII, pp. 534-535.

21 Viney (1965) 206-207.

22 Díez-Picazo (1999) 354-355.
} 
ca obra, Aguiar señala que la idea de la previsibilidad de las consecuencias es central en la idea de la culpa. La culpa no requiere que el resultado se haya previsto. En cambio, en la culpa el resultado no se prevé, pero sí puede haberse previsto. En este sentido, es la provocación de un resultado no previsto, pero sí previsible ${ }^{23}$. Y Colombo indica que la culpa existe cuando el individuo tiene la posibilidad de la previsión y la aptitud suficiente para que esa posibilidad exista. La previsión de las consecuencias se relaciona íntimamente con el individuo que lo comete, esto es, con el desarrollo de sus condiciones intelectuales y psicológicas y con las circunstancias de tiempo y lugar que lo rodean a ejecutarlo 24 .

Algunos civilistas, en época más reciente, también han sostenido que la culpa importa la omisión de la diligencia. Según Lacruz, la culpa supone un actuar imprevisor, descuidado o negligente que causa daño a otro y que mediante el empleo de la diligencia exigible en el tráfico pudo haberlo impedido, es decir, la diligencia que puede esperarse de un buen padre de familia, de un hombre razonable ${ }^{25}$. En Chile, es fiel reflejo de esta corriente la famosa definición de Abeliuk: culpa o descuido, nos dice el autor, es: "la falta de diligencia o cuidado en el cumplimiento de una obligación o en la ejecución de un hecho". Por mucho que afirma después que el criterio de valoración es el abstracto, la definición dice mucho de la forma de entender la culpa (desde la posibilidad y no del deber de previsión $)^{26}$.

Carbonnier, a nuestro juicio, es más explícito al afirmar el componente psicológico, tanto de la faute como de la culpa estricta, por sobre cualquier otra consideración de orden normativo. Por ejemplo, indica que la responsabilidad fundada en la culpa encuentra su base en el estado de ánimo del individuo, subordinando la reparación a una averiguación psicológica. Considera que la culpa se traduce en un reproche social, que el demandado ha observado y en el que podía no haber incurrido, de haberlo querido así. Se compone, según Carbonnier, de tres elementos: a) un hecho del hombre, como exige el artículo 1382, sea este por comisión u omisión; b) un elemento psicológico, traducido en la voluntad que hubiera podido desviar el curso de los acontecimientos; c) un elemento

23 Aguiar, Henoch (1950), Manual de Derecho Civil, t III: Hechos y Actos Jurídicos. Responsabilidad Civil, Buenos Aires: TEA, p. 263.

24 Colombo, Leonardo (1965), Culpa aquiliana. Cuasidelitos, Buenos Aires: Ediciones La Ley, $3^{a}$ edición actualizada, pp. 226; 230.

25 Lacruz Berdejo, José Luis (1999), Elementos de Derecho Civil, t. II, vol. II: Derecho de obligaciones. Contratos y cuasicontratos. Delitos y cuasidelitos Madrid: Dykinson, revisada y puesta al día por Francisco Rivero Hernández, p. 125.

Véase Abeliuk Manasevic, René (2003), Las obligaciones, Santiago: Editorial Jurídica de Chile, reimpresión $4^{\mathrm{a}}$ edición, p. 737. 
sociológico, es decir, la reprobación social de la conducta del demandado, que reposa en el injusto de su actuación ${ }^{27}$.

Debemos coincidir con el profesor Díez-Picazo en el sentido que se trata de una tesis abandonada, pero no puede dejar de mencionarse que en la crítica hay un discurso bastante recurrente, que estima que la culpa codificada era un elemento reconocidamente insuficiente para la sociedad industrial, debido a su naturaleza moral y psicológica.

Siguiendo a Bartoli, hay dos formas que permiten determinar cuándo un sujeto podía haber actuado de otra manera: o bien se atiende a las circunstancias concretas del sujeto, que se corresponde con lo que en responsabilidad civil se denomina valoración en concreto de la culpa o diligencia quam suis, es decir, la diligencia que uno pone en los asuntos propios; bien asumir el punto de vista del concepto normativo que importa elaborar un juicio abstracto y preguntarse si un hombre medio se hubiese comportado de manera diversa, lo que en palabras de Bartoli implica la búsqueda de un modelo de regularidad psíquica, en el sentido que: "le linee essenziali del suo procedimento motivazionale sono prive di vizi e anomalie come quelle di un nomo che si asume come normale"28.

\section{3) EL CONCEPTO ÉTICO DE LA CULPA: EL JUICIO DE CULPA COMO REPROCHE PERSONAL}

En la dogmática constituye un lugar común que acompaña cualquier explicación sobre el origen y consagración de la culpa, afirmar que esta se confunde o se traduce en un reproche moral. Y ello vale tanto para el ataque más descarnado a la culpa, como para la defensa más acérrima, como para describir, simplemente, la evolución desde la culpa a la paulatina objetivación. Tomemos nota de algunos ejemplos. Borda se preocupa de dirigir sendos ataques al mito, a la idea que en toda las reglas de responsabilidad hay un problema de culpa y lo hace desde una visión psicológica del instituto, pero además, nos dice que la ilicitud envuelve un juicio moral del sujeto que ha cometido el acto dañoso, adecuándose entonces a los actos personales del autor, pero fuera de ese radio, es decir, en la responsabilidad por hecho ajeno y hecho de la cosas, la reparación se fundaría simplemente en el riesgo creado ${ }^{29}$.

27 Carbonnier, Jean (1971), Derecho Civil. Estudio Introductorio, t. II, vol. III: Situaciones extracontractuales y dinámica de las obligaciones, trad. de la $1^{\text {a }}$ edición francesa por Manuel $\mathrm{M}^{\mathrm{a}}$ Zorrilla Ruiz, Barcelona: Bosch, pp. 55-56; 82 y ss.

28 Bartoli, Roberto (2005), Colpevolezza: tra personalismo e prevenzione, Torino: Giappichelli, pp. 65-70. Una posición similar a la descrita por Bartoli asume CARbonnier (1971) 85 para la culpa estricta, al indicar que en esta hay siempre una opción capaz de alterar el acontecer causal.

29 Borda, Guillermo A. (2000), "Fundamento de la responsabilidad extracontractual”, en Atilio Aníbal Alterini (director): Responsabilidad civil y seguros, Buenos Aires: La Ley, pp. 1012 
Otros autores emplean los mismos argumentos para una defensa acérrima de la culpa, considerando regresivos aquellos factores que fundan la responsabilidad en la pura causalidad material y no en el comportamiento o la conducta del agente. La culpa, de otra parte, es afirmada derechamente como reproche moral, para defender un sostén o sustento ético de la responsabilidad ${ }^{30}$. Y todavía un tercer grupo, de manera bastante frecuente, por cierto, al explicar el estado actual, el producto de la evolución, opone a la culpa subjetiva una responsabilidad objetiva que enfatiza el nexo causal. Ahora bien, cuando se desplaza el problema al análisis de la relación de causalidad, no se consideran los elementos normativos que deben concurrir en su configuración ${ }^{31}$.

y ss. De paso digamos que muchas críticas que el autor formula a la culpa no dicen relación con su estructura, ni con su esencia, sino con la política legislativa que la ha consagrado de tal o cual forma. Los planos debiesen separarse, pero a menudo no ocurre así. Por ejemplo, Borda estima que es una insuficiencia del sistema basado en la culpa la circunstancia que los menores de 10 ańos o dementes -se entiende, en el sistema argentino- no respondan. Se trata, si se quiere, de una cuestión de lege ferenda, porque varios sistemas contemplan la responsabilidad vicaria en el supuesto de incapaces extracontractuales.

30 Llambías, Jorge Joaquín (2000), "El derecho no es una física de las acciones humanas. Reflexiones sobre el fundamento de la responsabilidad civil. Ámbito de aplicabilidad y extensión del resarcimiento. Culpa y riesgo creado", en Atilio Aníbal Alterini (director): Responsabilidad civil y seguros, Buenos Aires: La Ley, pp. 1039 y ss.

31 No es una sorpresa que si tomamos cualquier texto sobre responsabilidad del Estado, en cualquier sistema en el que se haya "avanzado" hacia la objetivación y encontrará opiniones como las que siguen. Para el caso español. Por ejemplo, Martín Rebollo, Luis (2007), "Fundamento y función de la responsabilidad del Estado", en Juan Antonio Moreno Martínez (coordinador): La responsabilidad civil y su problemática actual, Madrid: Dykinson, p. 551, quien caracteriza dicho sistema de responsabilidad como objetivo: "Una de las caracteristicas fundamentales del sistema español de responsabilidad extracontractual de las Administraciones Públicas es que se prescinde de la idea de culpa para fundamentar la consecuencia de la indemnización". Agrega: "Frente al tradicional criterio subjetivo de la culpa o la negligencia se alza, pues, un principio de responsabilidad objetiva...", principio que desde luego es entendido como la comprobación del simple vínculo causal: "Por tanto, no es necesario demostrar su existencia -de la culpa-, sino únicamente la realidad de una lesión imputable causalmente a la Administración de que se trate".

Pero también en el terreno del derecho privado hay expresiones similares, como las de O' Callaghan Muñoz, Xavier (2007), "La responsabilidad objetiva”, en Juan Antonio Moreno Martínez (coordinador): La responsabilidad civil y su problemática actual Madrid, Dykinson, pp. 802-803. MuÑoz (2004) p. 3451, según quien, tradicionalmente las normas de responsabilidad importaron un reproche moral, asimilando la infracción normativa a un pecado, tal como se estableció en el período codificado. En un sentido similar, para otro sistema, como el argentino, se pronuncia, por ejemplo, Bustamante Alsina, Jorge (1997), "El perfil de la responsabilidad civil al finalizar el siglo XX", en Aída Kemelmajer de Carlucci y Jesús Alberto Bueres (directores): Responsabilidad por daños en el Tercer Milenio. Homenaje al profesor Doctor Atilio Aníbal Alterini, Buenos Aires: Abeledo-Perrot, p. 26, quien califica la culpa como una imputación moral. MAYO, Jorge A. (2001), "El ámbito de la culpa en el Derecho de obligaciones", en Oscar Ameal (director), Derecho privado. Libro homenaje a Alberto J. Bueres, Buenos Aires: Hammurabi, p. 1287, sostiene que considerada la culpa en su aspecto subjetivo, se dirige a individualizar la imprudencia, la negligencia, la impericia o la ligereza, pero en tal sentido se traduce en un juicio psicológico, dirigido al estado de ánimo 
Como se advierte, hay en estas posiciones dos equívocos que transforman toda discusión en un diálogo de sordos: de un lado, pensar en la culpa como un reproche moral, para defenderla o atacarla; de otro, estimar que en la responsabilidad por riesgo creado no hay cuestiones morales envueltas, porque la obligación de responder se satisface con la simple causalidad material. Ambos extremos deben descartase a nuestro juicio. En primer lugar, porque la culpa no se identifica con un reproche moral, lo que no significa para nada que no existan relaciones con la culpa moral o que deba negarse un juicio de reproche en el juicio de responsabilidad.

Además, debe destacarse que la culpa en responsabilidad civil no es subjetiva, en el entendido que surge como consecuencia de la infracción de un deber de cuidado (aunque no se reduzca a este) ${ }^{32}$. En segundo lugar, la causalidad no es un problema fáctico, pues no hay, en estricto rigor, en responsabilidad civil, una pura causalidad material, debiendo incorporarse a esta elementos normativos que deben ser apreciados a la hora de afirmar la causalidad. Precisamente por ello, el equívoco también queda superado a nuestro juicio, si uno asume la perspectiva de Medina, quien explica que no puede separarse absolutamente culpa y responsabilidad por riesgo, pues la segunda no es una responsabilidad sin culpa, sino una responsabilidad "aunque no haya culpa", agregando que no cabe fijar una frontera de incomunicación entre ambas hipótesis, pues la imputación objetiva del riesgo es solo una variante de la imputación subjetiva, caracterizada por su mayor espectro, absorbiendo el criterio del riesgo la culpa. Ello crea nuevos problemas de fronteras, si se quiere, entre culpa y causalidad ${ }^{33}$.

Se sostiene que Ripert es el principal representante de esta forma de concebir la faute. En su pensamiento, solo se podía estar frente a la idea de responsabilidad en el caso que existiese culpa, diferenciándola de la obligación legal de reparación, pero pensamos que el pensamiento de este gran jurista francés ha sido mal interpretado, porque una lectura

del agente, mientras que la culpa en sentido objetivo, importa la inobservancia de una norma.

32 En efecto, como indica Valdivia, José Miguel (2005), "Codificación del derecho de la responsabilidad del Estado, en María Dora Martinic G. y Mauricio Tapia R. (directores), Sesquicentenario del Código civil de Andrés Bello. Pasado, presente y futuro de la codificación, Santiago de Chile: LexisNexis, t. II, p. 880, utilizar la nomenclatura de subjetiva para la culpa es: "Inapropiada, primero, porque supone identificar la culpa con un estado subjetivo del autor del daño, en circunstancias que el juicio de reproche que la culpa supone no siempre recae sobre la voluntad o la psicología del agente. Bastaría simplemente analizar la tipología de las culpas en el derecho civil para convencerse de lo inadecuado de esta nomenclatura".

33 Medina (2004) pp. 3220-3221. De hecho Medina nos dice que en el criterio del riesgo hay que atender primero a la causalidad culpable, pero también y en defecto de esta, a la causalidad interna aportada por el agente. Es por ello que MAzeaud y Tunc (1978) t. III, vol. II, 19 criticaban a la doctrina del riesgo, precisamente porque la vida en sociedad siempre hay riesgos que son causados y asumidos. 
atenta de su obra quiere mostrar que detrás de cualquier regla de responsabilidad, hay una regla moral. Otra cosa es que fundara en eso la preeminencia de la culpa. Mirada así la cuestión, en la idea de Ripert no se encuentra el rechazo de una obligación de resarcimiento fundada en el riesgo, sino que, por el contrario, Ripert dirige sus críticas al modelo de la responsabilidad por el simple vínculo causal, cuestión en la que por lo demás, hay un relativo consenso. La ubicación dentro del concepto ético de la culpa se encuentra justificada, en cualquier caso, por la radicalidad del pensamiento en Ripert, explicable como reacción frente a ciertos excesos que a su juicio contenía el deber de reparar fundado en la responsabilidad estricta, por cuanto estimaba el jurista francés que era la faute misma el fundamento mismo de la obligación de resarcir ${ }^{34}$.

En la dogmática española puede ser ubicado en este grupo, sin duda alguna Santos Briz, cuyas ideas desarrollaremos en los párrafos que siguen. En principio, aclaremos por qué Santos Briz transita, a nuestro juicio, entre una concepción psicológica y otra normativa. Así ocurre por cuanto inserta la culpa y el dolo como elementos de una categoría superior, la culpabilidad, cuyo presupuesto de reproche reside en la imputabilidad. De paso, dígase que esta advertencia no la hacemos con espíritu crítico, sino solamente para destacar el lugar que la culpa estricta juega en su pensamiento. Santos Briz piensa que negligencia y dolo se encuentran insertos en la culpabilidad, con la que no se confunde, constituyendo esta última el requisito subjetivo de la responsabilidad. Mientras la culpabilidad envuelve un juicio de reproche al autor, la culpa estricta simplemente es una variación de la antijuridicidad ${ }^{35}$.

Pero hay que advertir que el pensamiento de Santos Briz está cargado de matices, pues admite parcialmente la introducción de un componente normativo en la culpabilidad: la consciencia de antijuridicidad para el dolo, en cambio la culpa queda satisfecha por su propia naturaleza normativa, pues el autor la reduce a la mera violación del deber de cuidado de acuerdo con el estándar objetivo. Incluso, llega a negar que en la culpa exista algo así como un error de conducta. Para Santos Briz, la culpa importa una conducta voluntaria contraria al deber de prevenir las consecuencias previsibles del hecho propio. No se requiere de la prevención, pero sí de la posibilidad de haber previsto y el elemento volitivo queda reemplazado por una conducta negligente: no se ha querido el efecto, pero

Ripert (1949) 224 y ss.

Véase Santos Briz, Jaime (director), Sierra Gil de la Cuesta, Ignacio (coordinador), González Poveda, Pedro, Martínez-Pereda Rodríguez, José Manuel y Paz Rubio, José María (2003), Tratado de Derecho Civil, t. III: Derecho de obligaciones, Barcelona: Bosch, p. 408 y SANTos BRIZ, Jaime (1984), “Comentarios al artículo 1902”, en Manuel Albaladejo (director), Comentarios al Código civil y compilaciones forales, Madrid: RDP, t. XXIV, pp. 112 y ss. 
no se ha observado lo necesario para evitarlo. La culpa estricta es así la no apreciación de la diligencia objetiva seguida ${ }^{36}$.

En suma, si la cuestión se considera en términos de culpabilidad, bien podría pensarse, como se ha argumentado, que Santos Briz sigue un esquema psicológico, pero si miramos la culpa estricta, claramente el pensamiento de Santos Briz debe ser ubicado en las corrientes normativas e incluso la más normativa de todas, al reducir la negligencia a la mera violación de una norma. Como repite el propio autor: "La precedente exposición, ya considere la culpa como variante de la antijuridicidad, ya como reproche juridico de la conducta de agente, o ya primero en un sentido y después en otro, según se distinga entre negligencia, como aspecto objetivo, y culpabilidad, como aspecto subjetivo de la responsabilidad... ”. Pero el carácter ético de su tesis, la tesitura moral viene determinada, a nuestro juicio, por el concepto de culpabilidad, porque Santos Briz juzga como un positivismo amoral reducir este elemento de reproche a la mera vulneración de la norma ${ }^{37}$.

Pero habrá que hacer una precisión más, porque a diferencia de la teorías normativas puras que veremos a continuación, Santos Briz afirma la existencia de un momento de antijuridicidad, lo que es razonable porque este autor entiende que existe un elemento de culpabilidad. Interesante resulta destacar que este autor entiende la antijuridicidad como el elemento que permite discriminar el radio de daños indemnizables, especialmente a través del mecanismo del fin de protección de la norma, que ahora es ubicado en la antijuridicidad ${ }^{38}$.

\section{4) LA POSICIÓN DOGMÁTICA MAYORITARIA: LA CULPA COMO CONCEPTO NORMATIVO}

\subsection{1) Tesis normativas versus psicológicas}

Una concepción normativa, al menos cómo esta es entendida en el Derecho penal, no se contrapone con una concepción psicológica de la culpa. Como indica Jiménez de Asúa, en las concepciones normativas de la culpa, al papel de la voluntariedad se le reconoce un algo más, en otros términos, la culpa ya no solo es aprehendida como una "pura" relación

\footnotetext{
36 SAntos Briz, Jaime (1991), La responsabilidad civil. Derecho sustantivo y procesal, Madrid: Montecorvo, 6a edición, pp. 42-61. SAnTos Briz (1984) 113-115.

37 Santos Briz (1991) 55; 61. Una posición similar sostiene Fernández Asiáin, Eugenio (1946), "La culpa extracontractual en el Derecho Navarro", en Revista Principe de Viana, XXV, pp. 17-18, quien distingue entre una culpabilidad como atribución de un acto jurídicamente reprochable a una persona y la culpa estricta o negligencia, como la omisión de las diligencias debidas en el cálculo de las consecuencias posibles y previsibles de un hecho.

38 Santos Briz (1991) 28-30. En el mismo sentido, en Santos Briz y Otros (2003) 398400 .
} 
psicológica, porque junto a la apreciación de los aspectos psicológicos, hay una valoración de la conducta de un sujeto, en términos que se le puede formular un reproche ${ }^{39}$.

Ciertamente, con los matices del caso, estas conclusiones son trasladables a la culpa estricta civil, puesto que respecto de ella se exige un componente psíquico, un mínimo que permite precisamente una valoración de la conducta. No es que en la culpa civil se demande un vínculo psíquico con las consecuencias, pero sí se nos exige que estemos en presencia de un sujeto a quien formular un juicio de exigibilidad (lo que supone que exista una conducta) y que ese sujeto sea imputable, que en su mínima expresión supone el control inicial de la situación (por ello es que un ebrio, en materia civil, responde de los daños que ha causado en dicho estado $)^{40}$. Su inclusión en los sistemas codificados está presente como presupuesto de la culpa.

Así, no puede postularse una oposición entre tesis psicológicas y normativas, dado que las segundas solo suponen una superación de las primeras, pero incorporándolas. Ahora bien, el problema de la normatividad de la culpa no queda de este modo resuelto, porque siguiendo a Luzón no hay una tesis normativa, pues con el término se quiere abarcar una serie de concepciones de la "culpabilidad penal" y no de la culpa estricta, pero todas coinciden, como dice el autor, en desplazar la base psicológica para hacerla recaer, indistintamente, ya en su reprobabilidad, ya en su contrariedad a las normas del deber ${ }^{41}$. Detengámonos un breve momento en esta cuestión para que entendamos exactamente qué importa una concepción normativa.

39 En este sentido, Jiménez de Asúa, Luis (1963), Tratado de Derecho Penal, vol. V: La culpabilidad, Buenos Aires: Losada, 2a edición, pp. 163-164. Véase también, Vela TreviÑo, Sergio (1997), Culpabilidad e inculpabilidad. Teoría del delito, México D.F.: Trillas, $3^{\mathrm{a}}$ reimpresión, 2a edición, pp. 180-185.

40 Desde luego no estamos en ningún caso en el terreno de la acción, puesto que, como indica Bueres, Alberto (1986), El acto ilícito, Buenos Aires: Hammurabi, pp. 42-43, la manifestación de voluntad humana, voluntaria e involuntaria, comprende los actos instintivos y habituales y fuera de él se encuentran solamente los actos reflejos, estados de inconsciencia total, o los que resultan de una fuerza irresistible. En un sentido similar, SANTOs BRIz (1991) 2627, indica: “...el concepto jurídico de la acción es distinto que el filosófico, que solo comprende el obrar querido. Aquél comprende, además, la producción de un resultado mediante un movimiento corporal o inconsciente, en tanto se dé la posibilidad de un control de la conciencia junto a la dirección de la voluntad (...) el agente ha de responder juridicamente también de aquellas consecuencias de su actuación relacionadas con sus acciones que no ha previsto y aún las que no ha querido, pero con las cuales, según la previsión humana, debió contar y que por ello han de considerarse controlables por él".

41 Luzón Domingo, Manuel (1980), Tratado de la culpabilidad y de la culpa penal. Con especial referencia a los delitos de imprudencia, Barcelona: Editorial Hispano-Europea, pp. 71; 89-94. 


\subsection{2) ¿Cuándo estamos frente a una tesis normativa?}

Bartoli distingue las siguientes concepciones sobre la culpabilidad: a) Las concepciones normativas de la culpa, en las que a su vez pueden diferenciarse entre normativa formal, que equivale a lo que se denomina la tesis imperativa de la culpa y que se traduce en la mera contraposición de la conducta con la norma, de modo que el autor concluye que no puede distinguirse de la antijuridicidad; b) una concepción normativa sustancial, la que importa un juicio de reprobación o reproche, aunque dentro de esta diferencie dos orientaciones. Según la primera, de origen germano, la culpabilidad es un reproche al agente por no haberse conformado a la norma, teniendo la posibilidad de hacerlo. El objeto del reproche es, según la opinión más acreditada, el comportamiento interior manifestado del sujeto contra los valores garantizados por el ordenamiento y el criterio está dado por la posibilidad de querer diversamente, de modo que la culpabilidad es un comportamiento interior contrario a la norma, pudiendo haberse adecuado a ella ${ }^{42}$. Para la otra orientación, desarrollada en Italia, la culpabilidad es un juicio que tiene no solo el procedimiento motivacional, sino también psicológico, es decir, considerando el comportamiento de hostilidad e indiferencia e incluso de desinterés manifestado contra los valores del ordenamiento ${ }^{43}$.

No es el objeto de este trabajo, desde luego, profundizar sobre el problema de las concepciones normativas de la culpabilidad o de la culpa en Derecho penal, pero para efectos de nuestro análisis solo quisiéramos indicar, de la mano de Melendos, que las distintas teorías normativas sobre la culpabilidad han girado históricamente en relación a la consciencia de antijuridicidad o en torno a la exigibilidad de la conducta, pero se presenta en esta materia un cúmulo de opiniones heterogéneas. Así, entender

42 Precisamente, como señala Fernández, Gonzalo D. (2003), "Estudio introductorio, Culpabilidad normativa y exigibilidad. (A propósito de la obra de Freudenthal)", al libro Culpabilidad y reproche en el Derecho Penal, de Berthold Freudenthal, trad. por José Luis Guzmán Dálbora, Montevideo, Buenos Aires: Editorial B de F, las raíces del concepto normativo de la culpabilidad se encuentran en Frank, Freudenthal y Goldschmidt. Ahora bien, como indica este autor, dicha noción se adaptó tanto a los últimos defensores del causalismo neoclásico, como Mezger, cuya culpabilidad comprendía dolo, culpa y un juicio de valor, como al finalismo de Welzel, en el que culpa y dolo, se trasladan al tipo, reportando la culpa un puro juicio de reproche.

43 Bartoli (2005) 49-58. En el terreno penal, donde tuvieron origen, siguiendo a LuzóN (1980) 205, todas estas teorías se mueven entre una culpa basada en la infracción de una norma o en la contrariedad de un deber de prudencia o diligencia. Como indica QuintaNo Ripollés, Antonio (1954), “Culpa e imprudencia en la doctrina y en la práctica”, en Anuario de Derecho Penal y Ciencias Penales, t. 7, 1, pp. 47-48, se trata de doctrinas de la antijuridicidad y doctrinas de la conducta contra el deber. Luzón (1980) 205 y ss., indica que mientras en la dogmática penal francesa se inclinó por la primera tesis -la mera infracción normativa-, la italiana prefirió definirla como la infracción de una norma de conducta, alcanzando, en cualquier caso, su máximo desarrollo en la dogmática alemana. 
la culpa desde la consciencia de antijuridicidad no significa negar un papel a la inexigibilidad y viceversa, pero todas estas presentan como notas comunes, tres aspectos: a) la imputabilidad, como presupuesto biológico, b) los problemas de conocimiento o cognoscibilidad de la antijuridicidad (elemento intelectual del reproche); c) la no exigibilidad, como elemento volitivo $^{44}$.

Sin duda alguna estas concepciones del Derecho penal, como en otros ámbitos, admiten una reflexión desde la responsabilidad civil y, desde luego, adaptadas a la realidad del ámbito aquiliano. Trasladado el problema a la dogmática sobre responsabilidad extracontractual, nos encontramos con un amplio radio de opiniones a propósito de la culpa, como analizamos en detalle, desde aquellas que vinculan la culpa exclusivamente con la infracción de una norma de cuidado, equiparándola a la antijuridicidad, hasta aquellos que entienden que el concepto normativo de la culpa también envuelve un juicio de reproche.

En la magnífica expresión de Maiorca, la iniuria, injusticia o antijuridicidad es el elemento central, el perno en torno al cual giran todos los otros elementos de la fórmula de responsabilidad, pero, agrega: “...è un perno ben poco solido, allo stato attuale di questi studi...". Identifica Maiorca, las siguientes concepciones sobre la injusticia, que se traducen en versiones de las tesis normativas: a) la consideración de la injusticia como elemento superfluo; b) la antijuridicidad definida no solo como violación de un deber, sino que como lesión de un derecho; c) la injusticia como un cualificante de otros elementos; d) como un carácter del hecho o del acto (como violación de una norma); e) como un carácter de la culpa; f) como un carácter del daño (como lesión de un derecho) ${ }^{45}$.

\subsection{3) La culpa como infracción de reglamentos: culpa contra la legalidad}

Maiorca precisa que esta concepción corresponde a la denominada normativa imperativista, que concibe la culpa como transgresión de un deber, estableciéndose un deber de diligencia, cuyo contenido, en definitiva, se encuentra en la regla del alterum non laedere. Agrega que la incerteza del contenido de este deber ha llevado a los autores a abandonar el concepto de culpa como deber de diligencia para identificarla como la

\footnotetext{
44 Melendos Pardos, Mariano (2002), El concepto material de culpabilidad y el principio de inexigibilidad. Sobre el nacimiento y evolución de las concepciones normativas, Granada: Comares, pp. 249 y ss.; 597 y ss.

45 Maiorca (1960) 547-548.
} 
iniuria, definiendo en ese caso simplemente la culpa como transgresión de un deber ${ }^{46}$.

La culpa como infracción normativa se traduce en lo que la dogmática chilena identifica, desde Alessandri, como la culpa contra la legalidad y se configura en las hipótesis en que la ley establece directamente el estándar de conducta. Es claro que dicho concepto puede aplicarse a esferas sociales limitadas, como por ejemplo, la responsabilidad civil derivada de accidentes de tránsito. En efecto, en la dogmática chilena, se considera que el análisis de la norma resulta inoficioso si se ha violado una obligación proveniente de una norma determinada. En particular Alessandri considera que esta culpa se configura cuando la autoridad establece claramente una prohibición, a objeto de precaver un perjuicio o daño, de modo que la violación de la prohibición se traduce en culpa ${ }^{47}$. Como explica Corral, el deber de cuidado no está constituido solo por el deber general del neminem laedere: "... sino que se ha explicitado en reglas, normas, reglamentos, que en forma expresa señalan cuál es el comportamiento cuidadoso exigido. En estos casos, el solo hecho de que el agente ha transgredido con su conducta la norma expresada da pie para considerar que ha existido culpa en su actuación" $" 48$. Para Barros, una de las formas de construcción del deber de cuidado, se encuentra en al violación de normas (legales o reglamentarias), destinadas a regular específicamente una actividad, a priori, peligrosa. En estos casos, según el autor, cuando el daño se produce por la violación normativa, el acto es tenido por ilícito, que Barros equipara a la culpa ${ }^{49}$.

\subsection{4) La culpa como infracción de un estándar social: la posición normativa sustancial}

Desde esta perspectiva, la culpa se traduce en un comportamiento inadecuado conforme a un estándar social, no en un catálogo de deberes,

46 Maiorca (1960) 537. Bueres, Alberto (2001), Derecho de Daños, Buenos Aires: Hammurabi, p. 329, quien explica: "Está muy claro que esta manera de enfocar la cuestión es errada, dado que violar el contrato -y, por tanto la ley-o violar lisa y llanamente la ley o el ordenamiento, configura simplemente una ilicitud objetiva (antijuridicidad). Ya a estas alturas del conocimiento de los presupuestos de la responsabilidad, es impensable que se confunda la antijuridicidad con la culpa -sin defecto de que ésta tenga en su conformación estructural una dosis de ilicitud (subjetiva)".

47 Alessandri Rodríguez, Arturo (2004), De la responsabilidad extracontractual en el Código Civil Chileno, Santiago: Editorial Jurídica de Chile, 2a edición, pp. 128-129. Sigue estrictamente esta posición, Abeliuk (2003) 210; Ramos Pazos, René (2006), De la responsabilidad extracontractual, Santiago: LexisNexis, $2^{\text {a }}$ edición, p. 53.

48 Corral (2004) 215.

49 Barros (2009) 98. Como indica el propio Barros (2009) 97; 132, en responsabilidad civil, la antijuridicidad no es nada más que el hecho culpable que causa daño y agrega que: "quien dice que un acto es culpable dice también que es antijuridico y viceversa". 
más o menos detallados. No se trata, ciertamente de una noción sociológica, sino al contrario, de una perspectiva puramente normativa, en la que no conducirse socialmente deriva de la armonización de las libertades, según la fórmula de Kant, en la que el Derecho es precisamente la coexistencia de tales libertades. Existe pues el deber no solo de hacernos soportar el riesgo de la vida conjunta, sino hacer al prójimo el bien que exigiríamos de él. De este modo, la forma en la que nos conducimos en libertad, en la que conciliamos nuestras libertades y nuestras conductas se determina mediante la apreciación en abstracto de la conducta, es decir, por comparación con un estándar medio, que podemos exigirnos entre todos, el buen padre de familia, el hombre razonable y prudente. La culpa es definida como el error de conducta que no lo habría cometido una persona cuidadosa situada en las mismas circunstancias externas ${ }^{50}$.

Queda así perfilada definitivamente la concepción normativa, de orden sustantivo en la responsabilidad civil, pues esta perspectiva no satisface el contenido de la diligencia con la simple vulneración de la norma, sino con la conducción en sociedad de acuerdo con un patrón ideal de comportamiento. Díez-Picazo encuentra las raíces desde las ideas formuladas para el Derecho penal por Engisch, sosteniendo que en la culpa hay, por un lado la infracción de un deber de cuidado exigible y, por otra, el poder individual para observar dicho deber de cuidado. Desde este punto de vista existe: "(...) el deber de cuidado interno y el deber de cuidado externo. El primero obliga (...) a advertir la presencia del peligro en su gravedad aproximada como presupuesto de toda acción prudente y es lo que Engisch llamaba 'deber de examen previo'. El segundo consiste en el deber de comportarse externamente conforme a la norma de cuidado previamente advertida... " 1 .

50 Mazeaud y Tunc (1977) t. III, vol. II, pp. 50; 52; 87: “¿Cuándo cabe decir que el autor del daño no ha obrado como habría sido preciso? Todo reside en eso. Resolver esa cuestión es definir la culpa; porque es establecer un criterio que permitirá distinguir el hecho culposo del no culposo". Díez-Picazo (1999) 357-358. Engisch es uno de los principales promotores de la culpabilidad normativa, pero ha de advertirse que el fundamento de su pensamiento gira en torno a la posibilidad de construir el reproche de la culpa desde la idea de la culpabilidad de carácter, oponiéndola a una culpabilidad del autor, en su pensamiento, propia de la moral. Ella supone abandonar la idea que el fundamento de la culpa se encuentra en el libre albedrío del sujeto. Habrá que referirse brevemente a Engisch para comprender este punto de vista. El trabajo capital en esta materia es sin duda alguna, ENGISCH, Karl (2006), La teoría de la libertad de la voluntad en la actual doctrina filosófica del Derecho penal, trad. de la edición de 1965 por José Luis Guzmán Dálbora, Montevideo, Buenos Aires: B de F, pp. 58 y ss. Engisch explica que mientras los clásicos, agrupados en torno a Binding, plantearon como fundamento de la culpa la libre voluntad del sujeto, los "modernos"; reunidos en torno a Liszt e influidos por ideas kantianas, argumentaron que en el ámbito de los fenómenos - no en el metafísico- rige invariable el principio de la causalidad, elaborando una propuesta determinista. Una tercera tendencia, por último, quiso preservar el reproche de la culpa sobre bases deterministas, representados especialmente por Merkel. De acuerdo con esta idea, las acciones están determinadas por nuestro carácter, pero a pesar de ello es posible formularle un reproche. Por su parte, Engisch, articulando sus ideas sobre bases de algunos idealistas alemanes (particularmente Schopenhauer), busca una vía intermedia desde el determinismo, 
En cuanto a la construcción de los deberes de conducta, Díez-Picazo reconoce que se trata de uno de los problemas fundamentales de la culpa y advierte cómo los tratadistas franceses, especialmente Mazeaud y Tunc, recurren al contenido de la culpa para resolver la cuestión. Díez-Picazo indica que para que exista negligencia, la infracción de normas de conducta tiene que ser reconocida como creación de un riesgo no permitido y, por lo mismo, es necesario atender a si la evitación del resultado dańoso se encuentra dentro del fin de protección de la norma, de modo que solo las conductas que se encuentren dentro del radio de protección de la norma podrían ser calificadas de negligencia ${ }^{52}$.

Para Reglero, la culpa equivale en responsabilidad civil a la negligencia y se traduce en la omisión, sin ánimo de dañar, de la diligencia exigible. Según el autor, en primer lugar la culpa importa un juicio de previsibilidad objetiva, de acuerdo a lo que un hombre razonable debió haber previsto. Pero además estima que la culpa supone un segundo test, de evitabilidad, en la medida que el sujeto disponía de los medios necesarios para impedirlo y no lo hizo o que recaía sobre él un deber de evitar un resultado, en un caso particular ${ }^{53}$.

En nuestra doctrina, la consideración de la culpa contra la legalidad no es obstáculo para estimar que el deber de cuidado se construye, del mismo modo, bien a partir de infracción de usos normativos, bien mediante la determinación del deber de cuidado por el juez; en otros términos, la aceptación de una concepción de la culpa normativa formal

al proponer una culpabilidad de carácter, articulada sobre las aptitudes de las personas, adquiridas o no, modificables o no, que representan el sello de la misma.

Lo cierto es que desde el último tercio del siglo XX, en la dogmática penal se había impulsado la disolución del juicio de reproche por razones preventivas, lo que condujo a una parte de la dogmática, como indica Fernández, a articular un Derecho penal no basado en el libre albedrío, desde que la libertad resulta un elemento empíricamente indemostrable. Véase Fernández, Gonzalo D. (2006), "Presentación: La cuestión de la libertad de voluntad en el derrotero de la teoría de la culpabilidad" al libro La teoría de la libertad de la voluntad en la actual doctrina filosófica del Derecho penal, de Karl Engisch, trad. de la edición alemana de 1965 por José Luis Guzmán Dálbora, Montevideo, Buenos Aires: Editorial B de F., p. 38. Por citar un ejemplo, Bartoli (2005) 59, estima que la culpa no puede fundarse en la posibilidad de querer diversamente, pues dicha voluntad es indemostrada, más precisamente, la libertad de querer es indemostrable, pero además el autor reprocha que la libertad para querer diversamente no entrega un valor, no es un parámetro, un criterio, sino un dato de hecho, en otros términos, que el poder querer no puede ser utilizado como criterio al interior de un juicio de reproche o incluso al interior de una concepción normativa de la culpa, porque no es un parámetro capaz de fundar un juicio valorativo, sino que representa una realidad empírica, a la que se le agrega un atributo de valor opinable.

52 Díez-Picazo (1999) 359-360. En Dímz-Picazo, Luis (2001), "La culpa en la responsabilidad civil extracontractual", en $A D C$, vol. 54, 3, pp. 111-112 se refiere a una cuestión similar, pero emplea un lenguaje más difuso, pues nos dice que para que exista culpa el dańante debe haberse encontrado en una situación de deber en relación con los bienes o intereses lesionados. 
convive con otra, sustancial, que refiere el comportamiento debido, en definitiva, a la decisión jurisdiccional. En cuanto a los usos normativos, Barros considera que se trata de: “(...) reglas conocidas espontáneamente como expresión de un buen comportamiento y de aquello que usualmente se tiene por debido y que se expresan en expectativas de seguridad dentro de cada tipo de actividad (...) A veces, estas reglas están formuladas en códigos de ética o de conducta, como los que rigen la actividad publicitaria o la de algunos colegios profesionales. Más frecuentemente se expresan en buenas prácticas profesionales o empresariales", advirtiendo, en todo caso, que tales reglas no pueden ser impuestas a terceros, ni menos al juez ${ }^{54}$.

En ausencia de usos normativos e incluso, a pesar de ellas, el estándar de conducta es construido por el juez. Algunos autores han propuesto que el estándar de conducta con el que debe construirse el juicio de culpa, es el del buen padre de familia. Es la posición de Alessandri, quien sostenía que para apreciar la culpa debía recurrirse al estándar del buen padre de familia, tanto porque el artículo 44, al definir la culpa, es aplicable el ámbito contractual, como porque el artículo 2323 recurre a dicho estándar para su determinación. Aun así, no propone un único modelo para todo tipo de situación, sino uno que puede variar según el tiempo, el lugar, la condición social, la profesión, en fin, las circunstancias denominadas externas, frente a aquellas internas, que no deben considerarse ${ }^{55}$. Esta misma posición adopta Corral ${ }^{56}$.

Aunque comparte el principio de la aplicabilidad del artículo 44, según Barros, la tendencia del Derecho comparado es considerar bien las expectativas recíprocas de comportamiento, bien el cuidado exigido a una persona razonable enfrentada en las mismas circunstancias, lo que le conduce a estimar que no puede haber otra conclusión que considerar el patrón de la culpa leva, consagrado en el artículo 44 del Código civil. Ahora bien, en concordancia con toda la doctrina chilena, Barros entiende que en la construcción del modelo es esencial la consideración de las circunstancias extrínsecas (lugar, medios, riesgos, costos, naturaleza de la actividad emprendida, derechos e intereses en juego). En cambio, en principio, considera que las circunstancias especiales del sujeto, aun aquellas que se discuten (como la edad, el sexo o las cualificaciones profesionales), porque, de ese modo, explica Barros, se corre el peligro de crear un estatuto de responsabilidad diferenciado según el sujeto ${ }^{57}$.

\footnotetext{
54 Barros (2009) 104. Antes Alessandri (2004) 132-133, había reconocido expresamente la configuración del deber de cuidado a partir de la infracción de reglas profesionales o bien de usos y hábitos. Véase también, en el mismo sentido, Rodríguez Grez (1999) 178-179. Alessandri (2004)126-127. La aplicación del artículo del artículo 44 se justifica, según el autor, porque a propósito de la culpa leve, dicha norma seńala: "Culpa o descuido, sin otra clasificación, significa culpa o descuido leve".

BARROS (2009) 84-89; 105-107.
} 


\section{3) NUESTRO PUNTO DE VISTA}

\section{1) NECESARIA APROXIMACIÓN DESDE EL FUNDAMENTO: LA CULPA NO ES UN REPROCHE MORAL}

Nosotros creemos que en relación con el concepto puede ensayarse una vía intermedia. A nuestro juicio, una reflexión puramente dogmática sobre el concepto de la culpa debe abordar tres cuestiones problemáticas: en primer lugar, debe separar el concepto de la culpa del fundamento de la responsabilidad civil, con lo que, mirado ahora desde esta perspectiva, permite visualizar mejor por qué la culpa estricta en responsabilidad civil no puede ser considerada en ningún caso un reproche de carácter moral. En segundo lugar, requiere el examen del componente psicológico en la culpa, indagación que permite determinar por qué en la culpa debemos referirnos a una deficiencia de conducta y no a un error intelectual o a un reproche motivacional. En tercer término, un concepto de la culpa estricta debe preguntarse por sus relaciones con la antijuridicidad, porque el tratamiento de las tesis normativas soslaya completamente la cuestión.

Comencemos, entonces, por el primer aspecto propuesto, es decir, por la necesidad de deslindar la culpa del fundamento de la responsabilidad. Desde luego, no es un tema que pueda despacharse de manera tan sencilla en este lugar, pero puede servir de punto de partida para nuestras reflexiones. Como indica Rodotà -aunque lo afirme para abandonar la culpa- no puede identificarse ilícito con responsabilidad, pues no están en una relación de causa a efecto, ni el ilícito constituye el fundamento de la responsabilidad ${ }^{58}$. En efecto, por fundamento hay que entender las razones que justifican un régimen de responsabilidad; en cambio, dicho régimen dice relación con las condiciones o elementos que lo configuran ${ }^{59}$.

58 Rodotà (1965) 53-55.

59 Barros (2009) 450 asocia la función compensatoria y con ella la culpa a la justicia correctiva, mientras que las reglas de prevención de accidentes se basan en la justicia distributiva. En este sentido también, por ejemplo, Montés Penadés, Vicente L. (2003), "Causalidad, imputación objetiva y culpa en la "concurrencia de culpas", en Antonio Cabanillas Sánchez y otros (coordinadores): Estudios juridicos en Homenaje al profesor Luis Diez-Picazo, t. II: Derecho Civil. Derecho de Obligaciones, Madrid: Thomson-Civitas, p. 2595, quien considera que la justicia correctiva fundamenta la responsabilidad por culpa, mientras que la responsabilidad por riesgo (más allá del razonable, del permitido) la responsabilidad estricta, ser fundaría en la justicia distributiva. Con todo, reconozcamos que en un sentido secundario es perfectamente posible hablar de fundamento, como lo hace la mayoría de la dogmática, para referirse, siguiendo a De Ángel (1993) 52 al motivo o la circunstancia que permite el nacimiento del deber de indemnizar y es que la conexión de la culpa con el fundamento primario de la responsabilidad es muy profunda, pues se encuentra especialmente vinculada desde las funciones del sistema de responsabilidad. La vinculación es bastante simple de apreciar desde la consideración de la culpa -y la responsabilidad- como ilicitud. 
En este sentido, hay un acuerdo sustancial entre los juristas a la hora de referirse al principio elemental que informa la disciplina la responsabilidad. Dicho principio no es otro que lo que se ha calificado como la más importante regla que gobierna la convivencia humana: el no causar daño a los demás ${ }^{60}$. A este principio se le puede buscar una justificación normativa, como correctamente hace a nuestro juicio Reglero, cuando encuentra las raíces del no causar daño a otro (en términos positivos, el derecho a ser indemnizado de todo perjuicio) en el texto constitucional español, especialmente tratándose de aquellos derechos reconocidos que protegen la persona y sus bienes más preciados ${ }^{61}$.

Pero, una mirada sustantiva, que indague más allá del referente dogmático, permite una mejor comprensión de lo que quiere expresarse. De Ángel entiende que la culpa es el elemento que mejor representa la perspectiva individual, como un mecanismo de resguardo de nuestra libertad y una garantía, un mecanismo de tutela para el perjudicado. Es decir, lo que con otras palabras Salvador Coderch, María Teresa Castiñeira y luego Díez-Picazo, de modo más general, denominaron como función de demarcación, en cuanto se trata de establecer una delimitación de fronteras entre los ámbitos de libertad de actuación y la protección de determinados bienes e intereses ${ }^{62}$.

$\mathrm{Y}$ no pretendemos a priori una preeminencia moral para la culpa por sobre cualquier otro elemento de imputación, porque el fundamento moral sirve de sustento también en los llamados sistemas "objetivos" o por riesgo, o de garantía y no solo por lo que se ha dicho, es decir, que en todo sistema resarcitorio está patente la tensión dialéctica dañante-da-

60 En este sentido, De Ángel (1993) 13. Reglero (2008) 49 advierte que se trata de uno de los pilares del Derecho, agregando que toda civilización ha generado mecanismos para sancionar el dańo causado a otras personas. Díez-Picazo (1999) 41, con unas ya clásicas palabras, pone de manifiesto la íntima relación entre este pilar o principio de responsabilidad y las funciones: "Con estos preceptos tratan de resolver los Códigos civiles argentino y español, de forma similar a lo que ocurre con los Códigos de otros paises, un problema social que todos los ordenamientos jurídicos tienen que afrontar y que se puede denominar grosso modo como la distribución de los infortunios. Cuando ocurre una desgracia, una calamidad o un accidente del que se siguen daños para las personas o para las cosas, hay que decidir si el que experimenta el daño no tiene otra posibilidad que la resignación (lo sufre él) o si puede esperar algo de los demás y, mejor, si tiene derecho a ello. Si la respuesta al interrogante abierto fuera esta última, tendriamos que movernos todavía entre las dos alternativas que han quedado dibujadas: o se crea un sistema de auxilios o de ayudas, lo que a su vez oscila entre la beneficencia y la seguridad social; o se establece un derecho subjetivo del perjudicado a reclamar de otros el importe en que se valore el daño. Solo en este último caso puede hablarse, en rigor, de indemnización, de derecho a la indemnización y, por consiguiente, de Derecho de daños".

61 Reglero (2008) 95: "Para una Constitución liberal democrática, la ley, la autonomía de la voluntad y la responsabilidad por daños son elementos irrenunciables a la hora de ordenar y regular las relaciones entre los ciudadanos".

62 De Ángel (1993) 192; Salvador y Castiñeira (1997) 103; Díez-Picazo (1999) 43; OWen (1997) 202 la libertad es uno de los más importantes y fundamentales valores morales que sustenta el edificio de la responsabilidad. 
ñado, sino porque las justificaciones mismas de tales sistemas recurren al final, a consideraciones morales ${ }^{63}$. Starck, el gran promotor de la teoría de la garantía, termina reflexionando en los mismos términos que De Ángel, es decir, ve en la responsabilidad un problema de límites a la libertad y una cuestión de enfoques. Starck considera el problema de la responsabilidad como un conflicto de derechos, pues afirma que frente a la libertad de actuar de un individuo se encuentra la seguridad de la víctima. Por tanto, la pregunta es si el autor tiene derecho a cometer tal dańo preciso. De esta forma, se enfrenta la libertad de acción del autor con la seguridad de la víctima.

Starck estima que el daño es la consecuencia normal de la acción libre de un hombre, de modo que el Derecho de daños o de seguridad, como lo llama, desaparece cuando la ley autoriza la comisión de este. En todo caso, el límite del ejercicio de las libertades se encuentra en determinados bienes fundamentales, como son la vida, la integridad corporal y de los bienes materiales, en cuyo caso, los atentados a estos no pueden constituir nunca un acto lícito. Es decir, todo daño no autorizado deviene en un daño ilícito que debe ser sancionado por el Derecho. De este modo, la sola violación de los derechos de otra persona basta para fundar la noción de responsabilidad ${ }^{64}$. Y sabemos que Rodotà, a pesar de afirmar categóricamente una separación entre la responsabilidad con cualquier orden moral, termina vinculando el injusto con el principio de solidaridad, respecto del que dice que se trata de un juicio de valor, que atiende a la situación de dañado ${ }^{65}$.

63 Como afirman Mazeaud y Tunc (1977) t. I, vol. 1, p. 5, no faltaron las corrientes objetivistas que en nombre de la moral y la equidad postulaban la adopción de la idea de riesgo. Ya hemos destacado, del mismo modo, cómo las corrientes del análisis económico del Derecho, sea para defender el establecimiento de una regla general de culpa o de responsabilidad estricta, encuentran fundamento en una más general regla de justicia. Y, siguiendo a DíezPicazo (2011) 114, un interesante ejemplo de lo que quiere señalarse se encuentra en las críticas a los sistemas de riesgo que se formularon desde el pensamiento marxista, y, por el contrario, la defensa de la idea de culpa, cuestión que a priori parecería una contradicción , pero que se explica porque es ahora la idea de la responsabilidad estricta y la de reparación de todos los dańos la que se aprecia como consecuencia o producto del capitalismo. Como dice el propio Díez-Picazo: "No puede discutirse la dosis de razón existente en las citadas observaciones de los juristas de corte marxista. Es dificil saber si la adopción en los casos en que se ha hecho, de los postulados de la doctrina del riesgo ha obedecido a una genuina necesidad de desarrollo capitalista o si se ha tratado solo de simples intuiciones de equidad. Es cierto, no obstante, que el sistema del riesgo cuadra mejor con las grandes empresas, que poseen un amplio dominio del mercado, que pueden calcular bien sus costos, que están en condiciones de contratar seguros y para las que no resulta difícil introducir la parte del costo de los seguros en los precios, trasladando tales costos a su clientela".

64 STARCK, Boris (1947), Essai d'une théorie générale de la responsabilité civile considérée en sa double fonction de garantie et de peine privée, Paris: Rodstein, pp. 19-20; 37.

65 Rodotà (1965) 109; 116. Uno de los principales impulsores del análisis económico del Derecho, London: Calabresi, Guido (1970), The costs of accidents. A legal and economic analysis, Yale University Press, New Haven, pp. 17; 24; 294-296 sostiene que el objetivo 
¿Adónde queremos llegar con estas consideraciones? Que no puede dudarse un carácter ético en el fundamento de juicio de responsabilidad y, por lo mismo, no puede desconocerse que la culpa contenga una base, un fundamento ético. Esto parece una petición de principio, pero muy a menudo se olvida, porque a propósito de los prejuicios que envuelven a la culpa, hemos advertido que suele ser rechazada porque esta representaría un reproche moral y una vinculación con la ética que no se correspondería con una construcción dogmática moderna de la responsabilidad. Otra cosa, desde luego, es cómo se concibe ese contenido moral, pero lo que aquí quiere destacarse es que todos recurren, en definitiva, a justificaciones de ese orden. Veamos brevemente qué queremos decir con esto.

Honoré nos advierte que la justicia correctiva, que es en definitiva el fundamento último de la limitación de libertad para los individuos, incluso si no hay culpa, es un principio sustantivo que tiene una base mo$\mathrm{ral}^{66}$. Precisamente, en el problema de la justicia es donde encontramos la discusión de fondo, que se encuentra latente en las diversas concepciones de la responsabilidad, de la culpa, de la responsabilidad estricta y de las relaciones de esta con la causalidad. El debate, con todo, ha tenido lugar especialmente en el ámbito de Common law, pero aplicable, por cierto, a la discusión del problema en el sistema chileno. No podemos detenernos en este gran debate, completamente ajeno al objeto perseguido en nuestro trabajo. En todo caso, siguiendo el trabajo de Perry, puede advertirse en esta materia dos criterios que han sido defendidos: el de la culpa, desde el análisis económico del Derecho, con Posner y desde el terreno de la moral, con Dworkin y Weinrib. En el caso de la responsabilidad estricta, en el campo económico con Calabresi y en el terreno moral con Epstein. Las posiciones desde la ética se encuentran fundadas todas desde la justicia correctiva, aunque esta, en uno u otro caso, se comprende desde muy diversos extremos ${ }^{67}$.

fundamental de todo sistema de Derecho de daños es la justicia y, solo en segundo lugar, la reducción del costo de los accidentes, de modo que es un error pensar, según este autor, que una sociedad buscará evitar accidentes a cualquier costo, porque ello llevaría a una paralización de las actividades sociales y aun más, indica que ningún sistema de responsabilidad puede funcionar si no se determinan a priori qué conductas son consideradas buenas, cuáles malas y cuáles neutrales, es decir, qué conductas son desaprobadas. Incluso cuando los jueces resuelven en un sistema objetivo, están envueltos por fuertes convicciones morales.

Honoré, Tony (1997), "The Morality of Tort Law. Questions and Answer, en David Owen (editor): Philosophical foundations of Tort Law, Oxford: Clarendon Paperbacks, p. 84. No es de extrañar que la regla del nemienm laedere haya sido calificada por RIPERT (1949) 198, derechamente como un principio de orden moral.

67 Perry, Stephen R. (1988), "The impossibility of General Strict liability", en Canadian Journal of Law and Jurisprudence, 1, pp. 147-148. Véase, sobre esta cuestión, el extenso trabajo de Wright, Richard W. (1992), "Sustantive Corrective Justice", en Iowa Law Review, 77, pp. 625 y ss., en el que nos muestra la afirmación de la culpa o de la responsabilidad estricta desde el formalismo kantiano o desde los voluntarismos y el enfoque sustantivo. 
Enseguida, ¿significa eso que la culpa constituye un reproche moral o que se identifica con este? Es una cuestión que hasta bien entrado este siglo viene afirmándose, pero que juzgamos un error, es decir, el de asociar la culpa jurídica con el pecado o en general con el reproche moral. No se trata de una distancia profunda, de una estructura diametralmente opuesta, sino al contrario, pero no puede juzgarse la culpa como equivalente a un reproche moral ${ }^{68}$. Tanto la culpa moral como la jurídica se presentan como conducta (acción), no efecto; reprobable en sí misma, pero cubierta, eliminada por el amor (la diligencia), la que, siguiendo a Maiorca, se nos presenta como una virtud del ser y así se dice que alguien "es" diligente ${ }^{69}$.

Con todo, no apreciamos entre ambas culpas una diferencia de estructura, sino de ámbito de acción. Negar la completa equiparación entre culpa jurídica y moral no importa negar a su vez que la culpa sea un reproche y reducirla consecuentemente a la mera vulneración de un deber. En las bellas palabras que empleó hace mucho tiempo ya Ripert: "la responsabilité civile n'est que l'organisation juridique technique de la responsabilité morale $" 70$. Como indica Barros, en ocasiones el Derecho es menos exigente que la moral para configurar la responsabilidad y como regla general, es más exigente, al presentar la culpa un cariz objetivo, pero el punto de confluencia se encuentra en que el Derecho representa un soporte de principios morales: "por un lado, su aparato de legislación y adjudicación permite precisar las reglas morales, cuyas condiciones de aplicación suelen ser más imprecisas; por otro, establece un estándar normativo común para todos,

68 La comprensión de la culpa como reproche moral ha suscitado las fundadas críticas, por ejemplo, de Alpa, Guido (1982), "Colpa e responsabilità nell'analisi economica del diritto", en Guido Alpa, Francesco Pulitini, Stefano Rodotà y Franco Romani (a cura di): Interpretazione giuridica e analisi economica, Milano: Giuffrè, pp. 534-535, pero que cae a nuestro juicio en el equívoco y, por consiguiente, en el falso argumento de contraponer al carácter subjetivo y moral de la culpa otra de corte objetivo y estandarizado. Una opinión menos radical encontramos en Honoré (1997) 80-82, quien piensa que no solo la culpa satisface las pretensiones de la justicia correctiva, de modo que una amplia opinión sobre esta conduce a pensar que puede y debe establecerse un régimen de responsabilidad estricta en supuestos en los que el sujeto tiene una posición de control sobre su comportamiento y en razón de ello causa daños, por comisión y omisión. Agrega que no es necesaria una actividad peligrosa para el establecimiento de una responsabilidad estricta, pues desde Aristóteles ya se diferenciaba entre una responsabilidad estricta y otra absoluta. Así, Honoré nos dice que: "When, however, there is no justification for inflicting a loss on another, outcome-responsibility supports the claim of corrective justice".

69 MaiorCa (1960) 575.

70 Ripert (1949) 218. Coincide en el mismo sentido Mayo (2001) 1287, quien indica que debe deslindarse la culpa moral de la jurídica, la que tiene su propio radio de acción, pero ello no implica negar la eticidad del Derecho y por ello sostiene que la culpa objetiva, como la mera infracción de normas, no puede ser articulada al deber recurrir a un entramado normativo que permitan comprender todas las hipótesis de negligencia. 
con un efecto de mediación entre percepciones diferentes acerca de lo útil y lo correcto, favoreciendo asi la cohesión social" 71.

Una excelente perspectiva de lo que viene argumentándose expone Castresana, a propósito del Derecho romano. Como dice esta autora, la esencia de la culpa se traduce en un acto libremente elegido. Hay culpa, nos dice, cuando el comportamiento elegido es reprobable por sobrepasar ciertos límites respecto del modelo de conducta alternativo. Agrega: "La culpa no supone la violación de cualquier norma, sino aquella violación que hubiera podido evitarse tanto desde el punto de vista material como de la conciencia del agente. La culpa individualiza, ha dicho Schipani, un motivo válido de sanción $y$, por ello, define un criterio de imputación dada la realización de comportamiento reprobable" 72 .

Ello nos debería conducir a dos conclusiones. Primero, que la culpa suponga un juicio de reproche no se opone para nada a que este sea como consecuencia o provenga de la vulneración de una norma alternativa o de cuidado, como se le quiera denominar. Otra cosa es que para destacar su carácter normativo y para evitar su confusión con la culpa moral o con

71 Barros Bourie, Enrique (2008), "La responsabilidad civil como Derecho privado. Notas sugeridas por la reseña de C. Rosenkrantz al Tratado de Responsabilidad Extracontractual”, en Estudios Públicos 112, p. 313.

72 Castresana, Amelia (2001), Nuevas lecturas de la responsabilidad aquiliana, Salamanca: Ediciones Universidad de Salamanca, pp. 70-71. La idea de que la culpa en el Derecho romano fue configurada, como criterio de imputación, en época posclásica, ha sido superada. La tesis esencial fue desarrollada por Arangio-Ruiz, V. (1958), Responsabilità conttratuale in Diritto romano, Napoli: Editricce Eugenio Jovene, reimpresión 2a edición, pp. 225 y ss. El esfuerzo dogmático decisivo en este sentido, pertenece, entre otros autores, a ScHipani, Sandro (1969), Responsabilità "Ex lege Aquilia". Criteri di imputazione e problema della "culpa”, Torino: Giappichelli, pp. 93 y ss. Para la tesis de Schipani, la culpa fue desarrollada en el período clásico. Según Schipani, tanto para los textos literarios como para los jurídicos, la culpa significaba siempre un hecho valorado desfavorablemente, un delictum, un peccatum, más genéricamente un malum, del cual el sujeto debía ser reconocido como autor, siendo esencial que el sujeto hubiere estado en condiciones de comportarse de otra manera y en la valoración de los eventuales impedimentos se consideraron factores externos e internos, los últimos inherentes a la voluntad y a la consciencia, pero no se requería la individualización de un comportamiento consciente y voluntario, bastando la no conformidad a un modelo de comportamiento. Véase en este sentido, Schipani, Sandro (2009), "Interpretazione della lex Aquilia nei giuristi replicani e il problema della culpa”, en El mismo: Contributi romanistici al sistema della responsabilità extraconttratuale, Torino: Giappichelli, p. 71. Dice Schipani: "Nella lingua latina, fino alla fine della reppublica, epoca della sua utilizazione tecnica da parte dei giuristi, il termine culpa era connesso alla presentazione di un fatto che costituisce un malum, e di cui una persona debe essere riconosciuta autore. È neccesario inoltre che tale persona possa comportarsi altrimenti, senza esservi impedita da fattori esterni (natura, deus, fatum, casus, necessitas, aliena vic ad potestas), od interni (imorudentia, inscientia, mancata previsione, lapsus, error), sempre che questi ultimi non siano riconducibili alla violazione di un modelo (per inertia, negligentia, fatuitas) di un modello di comportamento, per cui la sua condotta è passibile di una valutazione sfavorable, è essa stessa direttamente riprovebole”. Lamentablemente, la postura de Arangio-Ruiz, como hemos dicho, puesta en cuestión desde hace bastante tiempo en la romanística, sigue adoptándose irreflexivamente, como en otras materias, por la dogmática civil. Véase, como ejemplo, Dítz-Picazo (1999) 65 y ss. 
un juicio meramente psicológico, se le reduzca precisamente a esa norma. Además, las concepciones están cargadas de matices, porque es imposible negar que en la culpa hay un momento psicológico, por muy objetiva que esta sea, pues de otro modo deberíamos prescindir del requisito de la imputabilidad, en este sentido, hay un relativo consenso en el sentido que la culpa requiere un mínimo psíquico que satisfaga la comprensión de la infracción e incluso algunos han ido más allá, al proponer que la imputabilidad se traduzca en un presupuesto de todo tipo de responsabilidad ${ }^{73}$. Tomemos nota de un ejemplo. Planiol y Ripert defienden un concepto ético de la culpa, aunque consideran que esta se configura por la violación de una obligación de carácter genérico y, aun más, tratándose de la culpa estricta, se agrega que la negligencia y la imprudencia están compuestas por la posibilidad y el deber de prever y evitar, de acuerdo con el patrón del hombre medio o común, con el matiz que luego se afirma que, para atribuir el resultado a un sujeto, sea que se trate de una actuación u omisión dolosa o culposa, es necesario que dicha persona sea: "moralement responsable de ses actes". Vemos acá, en consecuencia, elementos propios de la tesis psicológica, la tesis ética y la normativa, porque la culpa estricta se describa de estos tres modos, en la medida que consideraciones morales y psicológicas, que en definitiva dicen relación estricta con la calificación del acto, son formuladas por estos autores. Se trata en consecuencia, de importantes matizaciones en la comprensión de la culpa como equivalente al ilícito ${ }^{74}$.

\section{2) LA RELACIÓN DE LA CULPA CON EL COMPONENTE PSICOLÓGICO: EL PLANO DOGMÁTICO}

De lo que se viene razonando, puede estimarse, en principio, que en la culpa estricta no hay consideraciones puramente psicológicas envueltas, salvo el elemento necesario para afirmar la imputabilidad. No es necesario recurrir a la efectiva previsión del sujeto, aun cuando, como indica López Olaciregui, la culpa supone la comisión de un hecho voluntario, pero que no se dirige, como en el dolo, a la conducta lesiva. Ello descarta que la culpa tenga un puro carácter psicológico, por cuanto ya desde el Derecho romano la culpa jurídica se conformaba con la posibilidad abstracta de previsibilidad o, como dice López Olaciregui, los hechos voluntarios son considerados formando una unidad con las circunstancias previsibles, de ahí que ciertas conductas puedan considerarse jurídicamente voluntarias,

En este sentido, Corral (2004) 106 y ss.

Planiol, Marcel y Ripert, Georges (1952), Traité pratique de Droit Civil Français, t. XVI: Obligations, Prémiere Partie, Paris: LGDJ, pp. 679; 689-705. 
aunque psicológicamente no se hayan ni querido, ni previsto ${ }^{75}$. En segundo lugar, que la culpa opera en una esfera distinta de la moral e incluso de la filosófica, no se traduce en que detrás de ella, como en el fundamento mismo de la responsabilidad, no exista uno de naturaleza moral, dado que no podemos fundar las normas solo en ellas o en criterios de racionalización económica ${ }^{76}$.

De modo que debe partirse del supuesto que en toda culpa hay voluntad. No se trata, por tanto, de un defecto de la misma, ni menos ausencia de ella, si se toma en consideración que la capacidad o la imputabilidad requiere un mínimo psíquico para atribuir culpa, como ocurre en todos los ordenamientos codificados. Como indica Díez-Picazo, la formulación de un juicio de culpabilidad requiere que en el sujeto concurran circunstancias necesarias para ello. Pero además, la culpa supone condiciones de libertad que permitan hacer exigibles las conductas, cuya ausencia se produce por el miedo insuperable o la fuerza irresistible ${ }^{77}$.

Puede concluirse, entonces, que en la culpa hay una deficiencia de conducta. Pero, ¿qué significa que esta sea una deficiencia de conduc-

75 López Olaciregui, José María (2007), "El derecho de la responsabilidad civil como un sistema de daños según principios subjetivos de justicia y equidad”, en Revista de Responsabilidad Civil y Seguros, IX, pp. 114-115. Y en la perspectiva de Corsaro, Luigi (2000), "Culpa y responsabilidad civil: la evolución del sistema italiano”, trad. por Josefa Torralba Alcalá, en Juan Antonio Moreno Martínez (coordinador): Perfiles de la responsabilidad en el Nuevo Milenio, Madrid: Dykinson, pp. 138-139, el reproche de la ley se refiere a la mala o débil voluntad de la persona que ha causado el hecho dañoso. Se trata de un defecto de voluntad, que no falta, agrega el autor, ni siquiera cuando se afirma que la valoración de la culpa es objetiva y abstracta, de modo que la culpa solo puede imputarse a quien puede reconocer y respetar los imperativos legales, pero agregando que se correspondía con el concepto de la culpa durante los primeros años de la codificación. Con todo, la crítica está salvada pues en el concepto de la culpa sin duda alguna debe admitirse aquella que se denomina inconsciente o sin previsión, porque en la culpa se reprocha, precisamente el no haber tenido en cuenta sus debilidades. Como indica Castresana (2001) 73, refiriéndose al Derecho romano: "Ésta -hablando de la culpa-, en tanto violación de una norma de conducta, se manifiesta en la actitud del agente que no ha tenido en cuenta su falta de idoneidad fisica o su incapacidad técnica como variables determinantes del damnum en ese caso".

76 Como indica Barros (2009) 24; 466, la culpa nos permite vivir en una atmósfera de libertad, porque evita la asfixia que produciría buscar siempre un responsable. En el mismo sentido, Bianca (1997) 130-140.

77 Díez-Picazo (1999) 364-365. Tampoco la culpa es puro defecto de intelecto, pues como señala Bueres (2001) 321: “...si se enlaza el susodicho intelecto con el discernimiento, pues éste, como ya se ha visto, es un primer estadio del acto voluntario, que resulta imprescindible para que quepa hablar de culpa (...) Y menos podría relacionarse el intelecto con la pericia del sujeto, pues si, en hipótesis, se pensara en un defecto del intelecto en esta dirección, se obtendría una visión parcelada y por demás imprecisa del instituto a definir". Habrá que concluir con Mezger, Edmundo (1956), "La culpabilidad en el moderno Derecho penal”, trad. por José María Navarrete, en Publicaciones de los Seminarios de la Facultad de Derecho Universidad de Valladolid, vol. 14, pp. 12-13, que la tesis psicológica se plantea como una relación de conocimiento entre el autor y el acto, de modo que no puede hablarse de culpabilidad cuando hay error en dicho conocimiento. De este modo, una posición normativa, como la que aquí se defiende, debe abandonar cualquier intento de vincular la culpa con el error intelectual. 
ta? Como explica Antunes, supone que el sujeto no solo se esfuerce por cumplir, sino que corrija sus propias imprecisiones naturales o su falta de preparación técnica y que, en último término, evite la práctica de los actos en los que carece de aptitud y precisamente por ello, nos parece a nosotros, puede negarse absolutamente el carácter de meramente psicológica a la culpa ${ }^{78}$. Por eso, como indica Maiorca, es un error considerar que la culpa equivale solo a la negligencia, traducida como un defecto de aquel esfuerzo, de aquella tensión de voluntad que uno podía o debía desplegar para impedir el resultado lesivo. Tampoco resuelve el problema la definición de la negligencia como incumplimiento o transgresión, porque no permite una explicación sustancial en la culpa traducida como impericia o imprudencia (y sus correlativos de pericia y prudencia). No se trata, agrega el autor, solo de admitir en la culpa la ausencia de esfuerzo -adecuada, pero no suficiente-, porque esta no permite explicar los otros matices de la institución. De este modo, el defecto de comportamiento significa que "tener" culpa implica un modo de ser - no una indagación psicológica- específico, en grado de conocer o poder prever la causa extraña del evento dañoso ${ }^{79}$. Como indica Bueres: "Visto asi el asunto, el debate acerca de si la culpa es una noción sicológica pura o una noción normativa pura pierde sentido - al menos en el campo del Derecho civil en el cual no hay controversias-. Por consiguiente es razonable asumir una posición intermedia: hay que tener en cuenta que existe una realidad subjetiva, sicológica (...) y, además, que la exigibilidad de la conducta por el ordenamiento hará desembocar la cuestión en el juicio de reproche. La culpa es pues, sicológiconormativa". Agrega: "Por otra parte, es inatacable que la culpa no es solo un

78 Véase Antunes Varela, Joao de Matos (1996), Das obrigaçòes em geral, Coimbra: Editorial Coimbra, 9a edición, vol. I, pp. 594; 598. Como indica Honoré, Tony (2002), "Responsibility and Luck. The moral basis of strict liability", en el mismo, Responsibility and fault, Oxford, Portland: Hart Publishing, pp. 16-21. Según el principio de la culpa, una persona es responsable solo cuando pudo haber controlado la situación en la que se encuentra, pero falla en ello. Solo si una persona podría haber actuado de otra forma es moralmente responsable y se requiere un reproche para su acción y, en el caso de la negligencia, él es responsable solo cuando podría haber actuado de acuerdo con el estándar requerido. La culpa no se traduce solo en una falta de carácter, sino en la necesidad de remediar dichas faltas para evitar un daño a otro. Según Honoré, Gayo fue el primero en desarrollar una teoría de la culpa, de origen jurídico, no filosófico y cita el conocido caso del muletero, en D. 9, 2, 8, 1, en el que hace responsable al muletero porque sabía o debía haber conocido su incompetencia antes de decidir manejar las mulas. Entonces el muletero o conoció su propia incompetencia o fue incapaz de verla -a sus propios ojos él era un hábil conductor-, pudiendo haberla visto. La culpa, así, puede servir para justificar un sistema en el que hay falla en las competencias.

79 Maiorca (1960) 549; 570-572. Agrega el autor que no es una indagación psicológica, sino que dice relación con la forma en la que el comportamiento se presenta, de acuerdo con los cánones de la experiencia. Si la causa extraña es concomitante al momento en el que el autor despliega su conducta, se puede hablar de cognoscibilidad del evento, es decir, previsión, representación; si la causa es sucesiva, se hablará de previsibilidad y no de previsión. Es por eso por lo que este autor describe en términos generales una concepción de esta naturaleza como normativa causal. 
descuido, una incuria, una desatención (mera relación sicológica) (...) La culpa, entonces, es un factor de atribución como cualquier otro; no es la regla general en este sentido, ni es un principio residual. Por consecuencia, se nos ocurre que la culpa es un defecto de conducta que repercute de forma negativa en las valoraciones que realiza la norma $y$, por lo mismo, es una razón de justicia adjudicar el daño al autor" 80 .

Hasta aquí podemos avanzar nuestras reflexiones, en lo que al objeto de nuestra indagación respecta, en cuanto a las relaciones entre la culpa y el componente psicológico. Ello nos ha permitido visualizar un elemento fundamental en el concepto de la culpa: la posibilidad de prever y la posición de evitación del sujeto.

\section{BIBLIOGRAFÍA}

- Abeliuk Manasevic, René (2003), Las obligaciones, Santiago: Editorial Jurídica de Chile, reimpresión $4^{a}$ edición

- Aedo Barrena, Cristián (2009), "La acto legis Aquiliae: concepto, características y desarrollo decretal posterior. Lecturas desde el capítulo tercero", en Revista de Derecho de la Universidad Católica del Norte, 16, 1.

- Aedo Barrena, Cristián (2010), "El uso de estacionamiento como acto de consumo. Reflexiones sobre la causalidad y la culpa. Comentario a la sentencia de la Corte de Apelaciones de Antofagasta, 30 de marzo de 2010", en Revista de Derecho de la Universidad Católica del Norte, $\mathrm{N}^{\circ} 1$.

- Aedo Barrena, Cristián (2012), "La función de la culpa en el sistema de la responsabilidad civil: una lectura desde el Derecho romano es posible", en Fabián Elorriaga de Bonis (coordinador): Estudios de Derecho Civil VII, Santiago: AbeledoPerrot-Thomson Reuters.

- Aguiar, Henoch (1950), Manual de Derecho Civil, t III: Hechos y Actos Jurídicos. Responsabilidad Civil, Buenos Aires: TEA.

- Alessandri Rodríguez, Arturo (2004), De la responsabilidad extracontractual en el Código Civil Chileno, Santiago: Editorial Jurídica de Chile, $2^{a}$ edición.

- Alpa, Guido y Bessone, Mario (1976), La responsabilità civile: illecito per colpa, rischio d'impresa, assicurazione, Milano: Giuffrè.

- Alpa, Guido (1982), "Colpa e responsabilità nell'analisi economica del diritto”, en Guido Alpa, Francesco Pulitini, Stefano Rodotà 
y Franco Romani (a cura di): Interpretazione giuridica e analisi economica, Milano: Giuffrè.

- Antunes Varela, Joao de Matos (1996), Das obrigaçòes em geral, Coimbra: Editorial Coimbra, 9a edición, vol. I.

- Arangio-Ruiz, V. (1958), Responsabilità conttratuale in Diritto romano, Napoli: Editricce Eugenio Jovene, reimpresión 2a edición.

- Asúa González, Clara I. (2008), en L. Fernando Reglero Campos (coordinador): Tratado de Responsabilidad Civil, cap. XIII: Responsabilidad Civil Médica, Madrid: Thomson-Aranzadi, 4a edición, t. II.

- Barros Bourie, Enrique (2005), “Justicia y eficiencia como fines del Derecho", en Juan Andrés Varas Braun y Susan Turner Saelzer (coordinadores): Estudios de Derecho Civil. Jornadas Nacionales de Derecho Civil. Valdivia. 2005, Santiago: LexisNexis.

- Barros Bourie, Enrique (2008), "La responsabilidad civil como Derecho privado. Notas sugeridas por la reseńa de C. Rosenkrantz al Tratado de Responsabilidad Extracontractual”, en Estudios Públicos 112.

- Barros Bourie, Enrique (2009), Tratado de Responsabilidad Extracontractual, Santiago: Editorial Jurídica de Chile, reimpresión de la $1^{\text {a }}$ edición.

- Bartoli, Roberto (2005), Colpevolezza: tra personalismo e prevenzione, Torino: Giappichelli.

- Bianca, Cesare Massimo (1997): "Supervivencia de la teoría de la culpa”, trad. por Alberto J Bueres, en Aída Kemelmajer de Carlucci y Jesús Alberto Bueres (directores): Responsabilidad por daños en el Tercer Milenio. Homenaje al profesor Doctor Atilio Anibal Alterini, Buenos Aires: Abeledo-Perrot.

- Borda, Guillermo A. (2000), "Fundamento de la responsabilidad extracontractual", en Atilio Aníbal Alterini (director): Responsabilidad civily seguros, Buenos Aires: La Ley.

- Bueres, Alberto (1986), El acto ilícito, Buenos Aires: Hammurabi.

- Bueres, Alberto (2001), Derecho de Daños, Buenos Aires: Hammurabi.

- Bustamante Alsina, Jorge (1997), "El perfil de la responsabilidad civil al finalizar el siglo XX”, en Aída Kemelmajer de Carlucci y Jesús Alberto Bueres (directores): Responsabilidad por daños en el Tercer Milenio. Homenaje al profesor Doctor Atilio Aníbal Alterini, Buenos Aires: Abeledo-Perrot.

- Calabresi, Guido (1970), The costs of accidents. A legal and economic analysis, Yale University Press, New Haven.

- Carbonnier, Jean (1971), Derecho Civil. Estudio Introductorio, t. II, vol. III: Situaciones extracontractuales y dinámica de las obligaciones, trad. de la $1^{\text {a }}$ edición francesa por Manuel $M^{\text {a }}$ Zorrilla Ruiz, Barcelona: Bosch. 
- Cárdenas Villarreal, Hugo y Moreno Molinet, Jaime (2011), Responsabilidad médica. Estándares jurisprudenciales de la falta de servicio, Santiago: Abeledo Perrot-Thomson Reuters.

- Castresana, Amelia (2001), Nuevas lecturas de la responsabilidad aquiliana, Salamanca: Ediciones Universidad de Salamanca.

- Corral Talciani, Hernán (2004), Lecciones de responsabilidad civil extracontractual, Santiago: Editorial Jurídica de Chile, reimpresión de la $1^{\text {a }}$ edición.

- Corsaro, Luigi (2000), "Culpa y responsabilidad civil: la evolución del sistema italiano", trad. por Josefa Torralba Alcalá, en Juan Antonio Moreno Martínez (coordinador): Perfiles de la responsabilidad en el Nuevo Milenio, Madrid: Dykinson.

- De Ángel Yágüez, Ricardo (1993), Tratado de responsabilidad civil, Madrid: Civitas, $3^{\text {a }}$ edición.

- De Ángel Yágüez, Ricardo (1994), "La responsabilidad civil de los profesionales y de las Administraciones sanitarias", en AA.VV.: La responsabilidad de los profesionales y de las Administraciones sanitarias, Sevilla: Consejería de Salud Junta de Andalucía.

- De Ángel Yágǘzz, Ricardo (1995), Algunas previsiones sobre el futuro de la responsabilidad civil (con especial atención a la reparación del daño), Madrid: Civitas.

- Díez-Picazo, Luis (1999), Derecho de Daños, Madrid: Civitas.

- Díez-Picazo, Luis (2001), "Culpa y riesgo en la responsabilidad civil extracontractual”, en Fernando Pantaleón (a cargo de): La responsabilidad en el Derecho, Madrid: AFDUAM.

- Díez-Picazo, Luis (2001), "La culpa en la responsabilidad civil extracontractual”, en $A D C$, vol. 54, 3.

- Díez-Picazo, Luis (2011), Fundamentos del Derecho Civil Patrimonial, $t$. V: La responsabilidad civil extracontractual, Madrid: Thomson-Reuters.

- Díez-Picazo, Luis y Gullón, Antonio (2005), Sistema de Derecho Civil, vol. II: El contrato en general. La relación obligatoria. Contratos en especial. Cuasicontratos. Enriquecimiento sin causa. Responsabilidad extracontractual, Madrid: Tecnos, $5^{\text {a }}$ reimpresión 9a edición.

- Engisch, Karl (2006), La teoría de la libertad de la voluntad en la actual doctrina filosófica del Derecho penal, trad. de la edición de 1965 por José Luis Guzmán Dálbora, Montevideo, Buenos Aires: B de F.

- Fernández Asiáin, Eugenio (1946), "La culpa extracontractual en el Derecho Navarro", en Revista Príncipe de Viana, XXV.

- Fernández, Gonzalo D. (2003), "Estudio introductorio, Culpabilidad normativa y exigibilidad. (A propósito de la obra de Freudenthal)", al libro Culpabilidad y reproche en el Derecho Penal, de Berthold Freudenthal, trad. por José Luis Guzmán Dálbora, Montevideo, Buenos Aires: Editorial B de F. 
- Fernández, Gonzalo D. (2006), "Presentación: La cuestión de la libertad de voluntad en el derrotero de la teoría de la culpabilidad" al libro La teoría de la libertad de la voluntad en la actual doctrina filosófica del Derecho penal, de Karl Engisch, trad. de la edición alemana de 1965 por José Luis Guzmán Dálbora, Montevideo, Buenos Aires: Editorial B de F.

- Ghersi, Carlos (1997), "Responsabilidad por actos lícitos", en Aída Kemelmajer de Carlucci y Jesús Alberto Bueres (directores): Responsabilidad por daños en el Tercer Milenio. Homenaje al profesor Doctor Atilio Anibal Alterini, Buenos Aires: Abeledo-Perrot.

- Honoré, Tony (1997), "The Morality of Tort Law. Questions and Answer, en David Owen (editor): Philosophical foundations of Tort Law, Oxford: Clarendon Paperbacks.

- Honoré, Tony (2002), "Responsibility and Luck. The moral basis of strict liability", en el mismo, Responsibility and fault, Oxford, Portland: Hart Publishing.

- Jiménez de Asúa, Luis (1963), Tratado de Derecho Penal, vol. V: La culpabilidad, Buenos Aires: Losada, 2a edición.

- Jourdain, Patrice (1994), Les principes de la responsabilité civile, Paris: Dalloz, 2a edición.

- Lacruz Berdejo, José Luis (1999), Elementos de Derecho Civil, t. II, vol. II: Derecho de obligaciones. Contratos y cuasicontratos. Delitos y cuasidelitos Madrid: Dykinson.

- Llamas Pombo, Eugenio (1999), Cumplimiento por equivalente y resarcimiento del daño al acreedor, Madrid: Trivium.

- Llamas Poмвo, Eugenio (2000), "Responsabilidad médica, culpa y carga de la prueba”, en Juan Antonio Moreno Martínez (coordinador): Perfiles de la responsabilidad en el Nuevo Milenio, Madrid: Dykinson.

- Llamas Pombo, Eugenio (2007), "Prevención y reparación, las dos caras del Derecho de dańos", en Juan Antonio Moreno Martínez (coordinador): La responsabilidad civil y su problemática actual, Madrid: Dykinson.

- Llambías, Jorge Joaquín (2000), “El derecho no es una física de las acciones humanas. Reflexiones sobre el fundamento de la responsabilidad civil. Ámbito de aplicabilidad y extensión del resarcimiento. Culpa y riesgo creado", en Atilio Aníbal Alterini (director): Responsabilidad civil y seguros, Buenos Aires: La Ley.

- López Olaciregui, José María (2007), "El derecho de la responsabilidad civil como un sistema de daños según principios subjetivos de justicia y equidad", en Revista de Responsabilidad Civil y Seguros, IX.

- Luzón Domingo, Manuel (1980), Tratado de la culpabilidad y de la culpa penal. Con especial referencia a los delitos de imprudencia, Barcelona: Editorial Hispano-Europea. 
- Maiorca, Carlo (1960), "Colpa civile. (teoría generale)", en Enciclopedia del Diritto, Milano: Guiffrè, t. VII.

- Martín Rebollo, Luis (2007), "Fundamento y función de la responsabilidad del Estado", en Juan Antonio Moreno Martínez (coordinador): La responsabilidad civil y su problemática actual, Madrid: Dykinson.

- Mazeaud, Henri, Mazeaud, Leon y Mazeaud, Jean (1978), Lecciones de Derecho Civil part. II, vol. II: La responsabilidad civil. Los cuasicontratos, trad. por Luis Alcalá Zamora y Castillo, Buenos Aires: Montchrestein.

- Mazeaud, Henri, Mazeaud, Léon, Tunc, André (1977), Tratado teórico y práctico de la responsabilidad civil delictual y contractual, trad. de la $5^{\text {a }}$ edición francesa por Santiago Sentis Melendo, Buenos Aires: Ediciones Jurídicas Europa-América, t. I, vol. I.

- Mayo, Jorge A. (2001), "El ámbito de la culpa en el Derecho de obligaciones", en Oscar Ameal (director), Derecho privado. Libro homenaje a Alberto J. Bueres, Buenos Aires: Hammurabi.

- Medina Alcoz, María (2003), La culpa de la víctima en la producción del daño extracontractual, Madrid: Dykinson.

- Medina Alcoz, María (2004), "El debate histórico de la subjetividad versus la objetividad de la responsabilidad civil en Francia y su proyección en España. El equilibrio de su convivencia actual en el Derecho espańol", en J.M. González Porras y F.P. Méndez González (coordinadores): Libro Homenaje al profesor Manuel Albaladejo García, Murcia: Colegio de Registradores de la Propiedad y Mercantiles de España, Universidad de Murcia, t. I.

- Melendos Pardos, Mariano (2002), El concepto material de culpabilidad y el principio de inexigibilidad. Sobre el nacimiento y evolución de las concepciones normativas, Granada: Comares.

- Messina de Estrella Gutiérrez, Graciela (1989), "Función actual de la responsabilidad civil", en Félix Trigo Represas y Rubén Stiglitz (directores): Derecho de Daños. Primera Parte, Buenos Aires: La Rocca.

- Mezger, Edmundo (1956), "La culpabilidad en el moderno Derecho penal", trad. por José María Navarrete, en Publicaciones de los Seminarios de la Facultad de Derecho Universidad de Valladolid, vol. 14.

- Montés Penadés, Vicente L. (2003), "Causalidad, imputación objetiva y culpa en la "concurrencia de culpas", en Antonio Cabanillas Sánchez y otros (coordinadores): Estudios jurídicos en Homenaje al profesor Luis Diez-Picazo, t. II: Derecho Civil. Derecho de Obligaciones, Madrid: Thomson-Civitas. 
- O’ Callaghan Muñoz, Xavier (2007), "La responsabilidad objetiva”, en Juan Antonio Moreno Martínez (coordinador): La responsabilidad civil y su problemática actual Madrid, Dykinson.

- Owen, David (1997), "Philosophical Foundations of fault in Tort Law", en el mismo (editor): Philosophical foundations of Tort Law, Oxford: Clarendon Paperbacks.

- Pantaleón, Fernando (1991), “Comentario al artículo 1902", en Cándido Paz-Ares Rodríguez, Luis Díez-Picazo Ponce de León, Rodrigo Bercovitz y Pablo Salvador Coderch (directores): Comentarios al Código Civil, Madrid: Ministerio de Justicia, t. II.

- Pantaleón Prieto, Fernando (2001), "Cómo repensar la responsabilidad civil (también de las Administraciones públicas)", en el mismo (a cargo de): La responsabilidad en el Derecho, Madrid: AFDUAM, pp. 175-177; también publicado en Juan Antonio Moreno Martínez (2000), Perfiles de la responsabilidad civil en el Nuevo Milenio, Madrid: Dykinson.

- Perry, Stephen R. (1988), "The impossibility of General Strict liability", en Canadian Journal of Law and Jurisprudence, 1.

- Planiol, Marcel y Ripert, Georges (1952), Traité pratique de Droit Civil Français, t. XVI: Obligations, Prémiere Partie, Paris: LGDJ.

- Quintano Ripollés, Antonio (1954), "Culpa e imprudencia en la doctrina y en la práctica”, en Anuario de Derecho Penal y Ciencias Penales, t. 7, 1 .

- Ramos Pazos, René (2006), De la responsabilidad extracontractual, Santiago: LexisNexis, 2a edición.

- Reglero Campos, L. Fernando (2008), en el mismo (coordinador), Tratado de Responsabilidad Civil, cap. II: Los sistemas de responsabilidad civil, Madrid: Thomson-Aranzadi, 4a edición, t. I.

- Ribot Igualada, Jordi (2003), "La culpa 'relevante' como culpa 'adicional': La STC 181/2000 a la luz de la interacción entre responsabilidad objetiva y culpa”, en Antonio Cabanillas Sánchez y otros (coordinadores): Estudios jurídicos en Homenaje al profesor Luis Diez-Picazo, t. II: Derecho Civil. Derecho de Obligaciones, Madrid: Thomson-Civitas.

- Ripert, Georges (1949), La règle morale dans les obligations civiles, París: LGDJ, $4^{\mathrm{a}}$ edición.

- Rodotà, Stefano (1965), Il problema della responsabilità civile, Milano: Giuffrè.

- Rodríguez Grez, Pablo (1999), Responsabilidad extracontractual, Santiago: Editorial Jurídica de Chile.

- Rogel Vide, Carlos (1977), La responsabilidad civil extracontractual. Introducción al estudio jurisprudencial, Madrid: Civitas. 
- Salvador Coderch, Pablo y Castiñeira Palou, María Teresa (1997), Prevenir y castigar. Libertad de información y expresión, tutela del honor y funciones del Derecho de daños, Barcelona: Marcial Pons.

- Salvador Coderch, Pablo y Gómez Ligüerre, Carlos (2005), "El derecho de daños y la minimización de los costes”, en Indret 1.

- Santos Briz, Jaime (director), Sierra Gil de la Cuesta, Ignacio (coordinador), González Poveda, Pedro, Martínez-Pereda Rodríguez, José Manuel y Paz Rubio, José María (2003), Tratado de Derecho Civil, t. III: Derecho de obligaciones, Barcelona: Bosch.

- Santos Briz, Jaime (1984), “Comentarios al artículo 1902", en Manuel Albaladejo (director), Comentarios al Código civil y compilaciones forales, Madrid: RDP, t. XXIV.

- SAntos Briz, Jaime (1991), La responsabilidad civil. Derecho sustantivo y procesal, Madrid: Montecorvo, $6^{\mathrm{a}}$ edición.

- Schipani, Sandro (1969), Responsabilità "Ex lege Aquilia”. Criteri di imputazione e problema della "culpa", Torino: Giappichelli.

- Schipani, Sandro (1995), "El sistema romano de la responsabilidad extracontractual: el principio de la culpa y el método de la tipicidad", en Aníbal Alterini, Alterini y López Cabana, Roberto (directores): La responsabilidad. Homenaje al profesor doctor Isidoro $H$. Goldenberg Buenos Aires: Abeledo Perrot.

- Schipani, Sandro (2009), "Interpretazione della lex Aquilia nei giuristi replicani e il problema della culpa”, en el mismo: Contributi romanistici al sistema della responsabilità extraconttratuale, Torino: Giappichelli.

- Starck, Boris (1947), Essai d'une théorie générale de la responsabilité civile considérée en sa double fonction de garantie et de peine privée, Paris: Rodstein.

- Tale, Camilo (1997), "La extensión del resarcimiento y otras cuestiones actuales de responsabilidad civil en la obra de Domat", en Diario El Derecho, Buenos Aires, 24 de julio.

- Valdivia, José Miguel (2005), "Codificación del derecho de la responsabilidad del Estado, en María Dora Martinic G. y Mauricio Tapia R. (directores), Sesquicentenario del Código civil de Andrés Bello. Pasado, presente y futuro de la codificación, Santiago de Chile: LexisNexis, t. II.

- Valls Portell, Roberto (1992), "El Derecho de Daños en la práctica actual”, en L. Ribó Durán (a cargo de): Derecho de Daños, Bosch: Barcelona.

- Vela Treviño, Sergio (1997), Culpabilidad e inculpabilidad. Teoría del delito, México D.F.: Trillas, $3^{\mathrm{a}}$ reimpresión, 2a edición.

- Viney, Geneviève (1965), Le déclin de la responsabilité individuelle, Paris: LGDJ. 
- Visintini, Giovanna (1999), Tratado de la responsabilidad civil, t. I: La culpa como criterio de imputación de la responsabilidad, trad. de la edición italiana de 1996 por Aída Kemelmajer de Carlucci, Buenos Aires: Astrea.

- Wright, Richard W. (1992), "Sustantive Corrective Justice", en Iowa Law Review, 77.

- Yzquierdo Tolsada, Mariano (2001), Sistema de responsabilidad civil contractual y extracontractual, Madrid: Dykinson. 